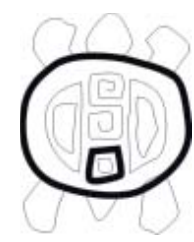

RMA

Dossier - Arqueología

\section{Puestos de altura de la Puna argentina: zooarqueología de Real Grande 1 y 6 y Alero Tomayoc}

Daniel E. Olivera' Jennifer L. Grant ${ }^{2}$

${ }^{1}$ CONICET, INAPL y Universidad de Buenos Aires. E-mail: deolivera@gmail.com ${ }^{2}$ CONICET, INAPL E-mail: jennygrant62@yahoo.com.ar

\begin{abstract}
Resumen
Las sociedades del Período Tardío en la Puna Argentina introdujeron sensibles mejoras técnicas y un aumento en la producción agrícola, relacionados con un proceso de cambio hacia una mayor complejidad socio-política. Existen grandes asentamientos poblacionales asociados a los campos de cultivo de los fondos de cuenca, pero los sistemas de asentamiento incluyen sitios ubicados en cotas más altas que aprovechan aleros y cuevas, denominados puestos de altura, como Real Grande 1 y 6 (Catamarca) y Alero Tomayoc (Jujuy).

Este trabajo apunta a estudiar los conjuntos arqueofaunísticos de los mencionados sitios a través de un análisis taxonómicoleconómico y osteométrico, para relacionarlo con la totalidad del contexto de los asentamientos. Los resultados parecen indicar que estos sitios cumplieron un rol importante para el pastoreo de llamas y la caza de camélidos silvestres (vicuña y guanaco) en las economías regionales. Más aún, los puestos de altura habrían desempeñado una función significativa al asegurar la circulación de información, bienes y energía apuntalando el proceso de complejización socio-política de las sociedades prehispánicas tardías de la Puna Argentina.
\end{abstract}

Palabras Clave: zooarqueología, osteometría, economía, puna, puestos de altura.

High elevation sites of the Argentine Puna: Zooarchaeology of Real Grande 1 and 6, and Alero Tomayoc.

\begin{abstract}
The societies from the Late Period in the Argentinean Puna introduced considerable technical improvements and an increase in agricultural production, in relationship with a process of change towards a greater sociopolitical complexity. For this period there are large settlements associated with crop fields in the low basins, but the settlement systems includes sites located at higher elevations, named "Puestos de altura" like Real Grande 1 y 6 (Catamarca) and Alero Tomayoc (Jujuy).

The aim of this work is to study faunal remains from the above mentioned sites through a taxonomical/economical and osteometrical analysis in order to relate them with the total context of the settlements. The results seem to show that these sites played an important role for the herding of llamas and the hunting of wild camelids (vicuña and guanaco) in the regional economy. Even more, the high elevation sites would have performed a vital function making possible the circulation of information, goods and energy giving strength to the process of sociopolitical complexity of the late prehispanic societies of the Argentinean Puna.
\end{abstract}

Keywords: zooarchaeology, osteometry, economy, puna, high elevation sites

Los camélidos sudamericanos han ocupado un lugar central en la evolución de las poblaciones prehispánicas que habitaron la Puna Argentina a lo largo del Holoceno. En los primeros momentos de ocupación del área (ca. 10.000 años AP), estos recursos eran obtenidos exclusivamente a través de la caza, pero posteriormente se desarrollaron procesos que llevaron a los grupos humanos a experimentar profundos cambios sociales y económicos. Los orígenes de estos cambios, que incluyeron la incorporación del pastoreo, la agricultura, la cerámica y el sedentarismo se remontan, por lo menos, a las etapas finales del Arcaico (ca. 4500 a 3000 años AP) e involucran un posible proceso de domesticación de la llama a nivel regional (Núñez y Santoro 1988, Olivera y Elkin 1994, Yacobaccio 1994). Sin embargo, se deben tener en cuenta dos elementos importantes: (1) los cambios en los sistemas de asentamientos no implicaron una reducción drástica de la movilidad, y (2) la caza de animales silvestres siguió constituyendo una estrategia destacada en la economía de las sociedades puneñas.

Los sistemas de asentamiento subsistencia de las sociedades agropastoriles puneñas incorporaban distintos microambientes con una oferta diferencial de recursos $y$, consecuentemente, involucraban varios tipos de asentamientos de funcionalidad y logística de ocupación diferente. En los sectores de cota más alta -ambiente de quebradas con pastos perennes y asociadas a vegetación de pajonal de altura-, se utilizaron puestos de actividades específicas y de ocupación no permanente, habitualmente 
relacionados con el pastoreo, la caza y la recolección. Sin dejar de lado la posibilidad de otros sectores de caza, estos ambientes son los preferidos por las vicuñas que evitan, en general, los sectores próximos a asentamientos humanos permanentes. En la actualidad, los fondos de cuenca de Antofagasta de la Sierra y de otros oasis de puna en general no son frecuentados por las vicuñas; aunque es posible que en la antigüedad los animales estuvieran más próximos, son numerosos los ejemplos de utilización de las cotas altas para la caza de vicuñas.

El objetivo de este trabajo es discutir el rol de estos puestos de altura en las estrategias económicas implementadas por sociedades agropastoriles prehispánicas tardías de la Puna argentina y su relación con el manejo de las diferentes especies de camélidos. Las economías de estas sociedades combinan, en diferentes proporciones, la producción de alimentos, pastoreo y agricultura, con la caza y la recolección, siendo los camélidos silvestres y domésticos el recurso faunístico dominante (López 2003, Izeta 2004, Olivera 1997).

Para determinar la importancia relativa de la cría de animales domésticos respecto de la caza de animales silvestres es necesario realizar análisis taxonómicos/ económicos de las muestras como así también refinar la identificación de las especímenes asignados a la familia Camelidae. Con ese fin, se han realizado análisis de muestras arqueofaunísticas de los sitios Real Grande 1 (RG1) y 6 (RG6) y Alero Tomayoc (Ty), afinándose estudios osteométricos sobre elementos del esqueleto post-craneal de las mismas.

Real Grande 1 y 6, ubicados en Antofagasta de la Sierra (Catamarca, Puna Meridional Argentina) fueron caracterizados como Puestos de Caza-Pastoreo de Altura, integrados en un sistema de asentamiento que incluye Bases Residenciales en sectores más bajos de la cuenca. Tomayoc, ubicado en la Sierra del Aguilar (Jujuy, Puna Septentrional Argentina), representa probablemente una instalación estacional ligada al pastoreo, quizás complementaria de una aldea permanente situada a cota menor (Lavallée et al. 1997).

Antes de meternos de lleno en el análisis del registro, se hace necesario realizar algunas observaciones sobre los conceptos de movilidad y subsistencia en los grupos puneños y una breve caracterización ambiental.

\section{Movilidad y subsistencia}

El modelo de Sedentarismo Dinámico (Olivera 1991) postula que el componente de movilidad presente en las estrategias pastoriles, relacionado con el acceso estacional a las pasturas, genera la presencia de distintos tipos de asentamientos. Estas instalaciones serían utilizadas diferencialmente a lo largo del ciclo anual, por lo que es esperable un cierto contraste en lo que respecta a su localización y organización interna. Estas características se traducirían en la existencia de diferentes tipos de asentamientos los que, dentro de un cierto rango de variabilidad, podrían agruparse en dos categorías básicas: (1) Bases Residenciales, de ocupación permanente o semi-permanente, ocupadas la mayor parte del año y en la que se desarrollan múltiples actividades a lo largo del ciclo anual, y (2) Puestos de Actividades Específicas, o asentamientos temporarios, a los cuales una parte del grupo se traslada periódicamente junto al ganado para acceder a las pasturas y/o para explotar ciertos recursos distantes de la base residencial; siendo la periodicidad, la recurrencia y la permanencia de la ocupación variables de acuerdo a las características de los recursos (López Campeny et al. 2005, Olivera 1991).

Sobre este esquema básico existe gran variabilidad en lo que respecta al número de puestos temporarios en uso, la distancia entre los distintos tipos de asentamientos, el tiempo de ocupación, la cantidad de gente que se traslada y las actividades desarrolladas, entre otras variables a considerar (Castro Lucic 2000, Göbel 1994, 2001, López Campeny et al. 2005, Merlino y Rabey 1978, Olivera 2006, Pagliaro 1995, Romo Marty 1998, Yacobaccio et al. 1997-1998, entre otros).

Una de las implicancias que se desprenden de este modelo de asentamiento, es que las diferencias funcionales entre los tipos de sitios que integran el sistema de asentamiento, se traducirían en un correlato distinguible en el registro arqueológico. Entre los materiales del mencionado registro los restos arqueofaunísticos, en particular los de la Familia Camelidae, ocupan un lugar destacado.

Pese a la importancia que las actividades agrícolas y pastoriles tuvieron en la economía de las sociedades prehistóricas desde los Período Formativo hasta el Tardío-Inca en el Noroeste Argentino, la caza de animales silvestres siguió siendo practicada con una intensidad variable según los casos (Grant 2008, Izeta 2004, Olivera 1997). La persistencia de esta actividad en sociedades pastoriles puede ser explicada por los potenciales beneficios de combinar ambas estrategias (Belotti López de Medina 2007, Escola 1996, Olivera 1997). En este sentido, Göebel (1994) propuso que entre los habitantes prehistóricos de la Puna la combinación de caza y pastoreo era una estrategia de diversificación que amortiguaba el riesgo económico, similar a la que implementan los pastores actuales cuando crían rebaños de distintas especies. Además, la caza disminuye la necesidad de sacrificar animales domésticos, lo cual es muy importante si estos son criados como una forma de almacenamiento o para la obtención de productos secundarios (Olivera 1997). Por otra parte, los movimientos estacionales vinculados al pastoreo pueden aprovecharse para practicar la caza de camélidos silvestres (Olivera 1991, 1997). De esta manera, esas actividades de caza en sociedades pastoriles de la Puna, si bien se practicaban de manera regular, pueden ser vistas como un mecanismo útil para preservar los rebaños de una matanza excesiva, en previsión de épocas de escasez, 
aliviando las presiones sobre las poblaciones de animales domésticos y permitiendo disminuir el riesgo económico asociado a la especialización en un único recurso.

Así, el advenimiento de las estrategias productoras durante el Formativo no habría implicado una disminución drástica de la movilidad, sino más bien una reorganización de la misma para el aprovechamiento de los distintos recursos que ofrecen los diferentes sectores ambientales, entre ellos los de caza y recolección. Esto implicaría una reorganización de las fuerzas y los tiempos de trabajo, repartiendo las tareas asociadas al pastoreo, a la agricultura y a la caza-recolección a lo largo del ciclo anual (Escola 1996, Olivera 2006). Aún es prematuro, dado el avance de las investigaciones, si esta reorganización estuvo asociada a parámetros de género, edad o situación social, pero muy posiblemente tuvo que ver con diferentes combinaciones de algunos de estos parámetros dependiendo de cada grupo social.

Para momentos más tardíos del proceso agropastoril, a partir de aproximadamente los 900-1000 años AP, se evidencia una creciente complejidad social y política asociada con el surgimiento de una organización social no igualitaria, un aumento de la densidad demográfica y el desarrollo de grandes poblados semiurbanos (ver, p.e., Tarragó 2000, Olivera y Vigliani 2000-2002). Durante estas épocas tardías, sin embargo, no decrece sino que parece aumentar la importancia del uso de diferentes microambientes ubicados a variada cota altitudinal, continuando el aprovechamiento de los sectores de pastura de las vegas altas y el pajonal. Si bien, por lo general, se observa un incremento de las estrategias agrícolas extensivas junto con nuevas tecnologías hidráulicas, la caza sigue acompañando al pastoreo como un complemento importante. Este componente cazador varía de acuerdo a los sitios y el momento considerado (Grant 2008, López 2003, Olivera y Grant 2009, Olivera 1997).

De manera que la alta dinámica logística, la integración de diversas estrategias económicas y el aprovechamiento integrado de todos los sectores ambientales de las cuencas parecen ser claves para los sistemas de asentamientosubsistencia tardíos.

Asimismo, la interacción con otras regiones no solo continúa sino que parece ser fundamental dentro del proceso tardío, quizás asociado a una institucionalización de las prácticas caravaneras relacionada al proceso de complejidad sociopolítica (Olivera y Vigliani 2000-2002).

\section{El ambiente en la Puna de Atacama}

La Puna Argentina se encuentra ubicada geográficamente entre los $22^{\circ}$ y $27^{\circ} \mathrm{S}$ y entre los $65^{\circ} 10^{\prime}$ y $68^{\circ} 50^{\prime} \mathrm{O}$, dividiéndose en un sector Septentrional y uno Meridional a la altura del paralelo $24^{\circ} \mathrm{S}$ (Fergulio 1946, en Escola 1999). Es parte integrante de la Puna de Atacama, siendo ésta la continuación del Altiplano Peruano- Boliviano.
Abarca las provincias de Salta, Jujuy, Catamarca y según como se definan sus límites puede alcanzar sectores de las provincias de La Rioja y San Juan.

La Puna consiste en un extenso altiplano situado entre los dos brazos en que se abre la cordillera andina, aunque su interior está recorrido por numerosos cordones montañosos. La altura media registrada es de 3600 a 3800 msnm, con oscilaciones que van desde los 3000 hasta más de 6000 msnm.

Esta macro-región posee características climáticas y geológicas que la circunscriben a un bioma de desierto de altura (Muscio 1998-1999), presentando condiciones generales de gran aridez. Desde un punto de vista ambiental, el espacio puneño actual se caracteriza por tener un clima frío y árido (clima Árido Andino Puneño), con una intensa radiación solar debida a la altitud y una gran amplitud térmica diurna/nocturna. Además, posee una marcada estacionalidad con precipitaciones estivales pobres (0-700 mm), con baja presión atmosférica, y con una distribución irregular de nutrientes (Olivera 2006).

Sin embargo, estas características generales no implican un elevado grado de homogeneidad ambiental. Por el contrario, es posible distinguir en el ámbito de la Puna importantes variaciones en el clima, la topografía, la geología y la biomasa. Las precipitaciones y la humedad del ambiente por ejemplo, disminuyen con el incremento de la latitud y en dirección este-oeste (Olivera y Elkin 1994, Yacobaccio et al. 1994).

En este sentido, en base a criterios geográficos, ecológicos y de variación de aridez se puede distinguir dentro de un mismo marco desértico, dos grandes sectores de la Puna Argentina con características ambientales algo diferentes (Santoro y Nuñez 1987): (a) Puna Seca, localizada en la porción noroeste y siendo la zona más húmeda y (b) Puna Salada, conteniendo extensas zonas con salares y salinas, resultado de una humedad reducida y de altas tasas de evaporación, lo que indica una condición más seca (Yacobaccio 1994).

Un punto importante es la impredictibilidad del clima puneño en el corto y mediano plazo. Las lluvias de régimen estival son muy irregulares, pudiendo alternar períodos de algunos años de sequía extrema con otros que son más abundantes, siendo casi impredecibles las condiciones de año a año, lo cual afecta drásticamente la disponibilidad de recursos. Asimismo, la aparición de heladas, nevadas, y vientos fuertes es poco predecible (Escola 1999).

Por su parte, la distribución de recursos no es homogénea distinguiéndose Zonas de Concentración de Nutrientes (sensu Yacobaccio 1994) frente a otras zonas con recursos muy dispersos o prácticamente inexistentes. Esto implica que la localización espacial de los recursos es predecible, pero no lo es su abundancia dado que el ambiente es, como se mencionó previamente, extremadamente va- 
riable en el corto plazo lo que provoca un alto grado de incertidumbre (Yacobaccio 1994).

Así, la distribución heterogénea de los recursos, la alta estacionalidad y, principalmente, la variación impredecible de las precipitaciones que afectan la disponibilidad de recursos, convierten a la Puna, en tanto desierto de altura (más de 3000 msnm), en un ambiente de alto riesgo (sensu Winterhalder et al. 1999).

Para los intereses de este trabajo, que apuntan a determinar la asociación de sitios en cotas altas con prácticas cazadoras, resulta interesante remarcar que, más allá de las indudables diferencias ambientales entre la puna seca y la salada, la disponibilidad de recursos de animales silvestres está asociada en los sitios considerados. No pretendemos avanzar en una comparación evaluativa profunda entre todos los aspectos que los sitios de altura pueden haber tenido para los sistemas de asentamiento-subsistencia puneños. Es posible que más allá de su rol para obtención de presas silvestres puedan existir diferencias de otro tipo asociadas a otras esferas de la sociedad (agricultura, recolección, ritual, etc.), donde diferencias ambientales incluso a nivel micro deberían ser consideradas en mayor profundidad. Sin embargo, como se sostuviera en un trabajo sobre el tema (Olivera y Goñi 1996) aparentemente la caza de camélidos actuó como variable independiente en este tipo de sitios no solo en la puna, sino también en algunos asentamientos patagónicos.

\section{Descripción General de los sitios analizados}

En este trabajo se analizaron conjuntos arqueofaunísticos de tres sitios de la Puna Argentina: Real Grande 1 y 6 (Antofagasta de la Sierra, Provincia de Catamarca), en la Puna Meridional Argentina y Alero Tomayoc (Sierra del Aguilar, Provincia de Jujuy), ubicado en la Puna Septentrional Argentina (ver Figura 1).

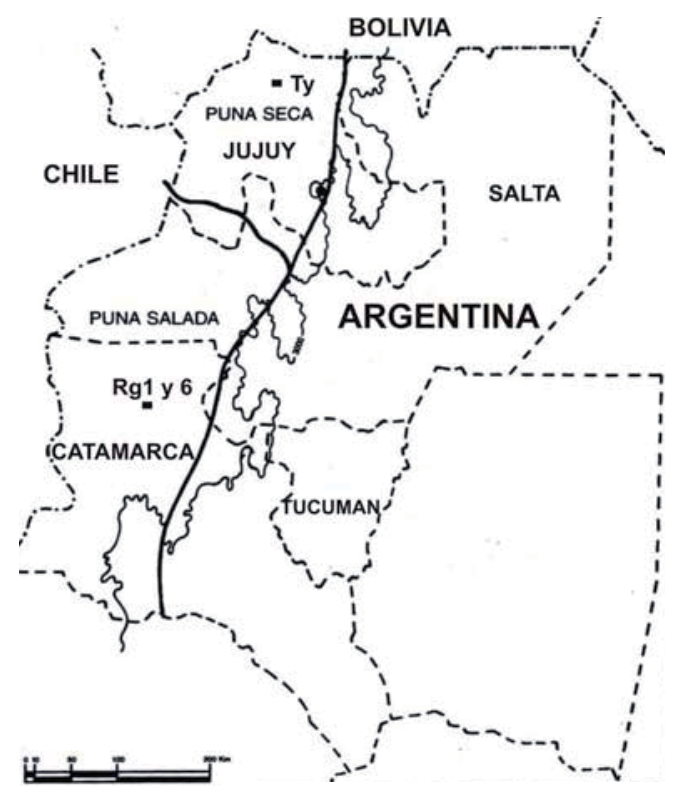

Figura 1. Ubicación de los sitios Real Grande 1 y 6.

En la Tabla 1 se incluyen los fechados C14 disponibles para los tres sitios. Si bien Ty presenta ocupaciones anteriores que llegan hasta el Período Arcaico solo se consideran aquí las ocupaciones coincidentes con el Tardío.

\section{Real Grande 1 (RG1)}

El sitio aprovecha un alero pequeño y el terreno adyacente, utilizado actualmente como corral, ubicados en las cercanías de la margen izquierda de la vega natural de Real Grande (4050 msnm). Este sector, situado en el curso medio/superior del río las Pitas posee abundantes recursos de agua y pastura durante todo el año. La etnoarqueología y la etnografía andinas señalan que este tipo de ambientes de vegas altas con pastos perennes se utilizan para pastoreo de invernada complementándolo con el Pajonal de altura (Olivera y Elkin 1994).

\begin{tabular}{|c|c|c|c|c|c|c|c|c|}
\hline Sitio & Nivel & Laboratorio & Código & Material & $\begin{array}{c}\text { Fecha } \\
\text { (Y.B.P. } \pm 1 \delta)\end{array}$ & $\begin{array}{c}\text { Fecha correg. } \\
\text { (Y.B.P.) }\end{array}$ & $\begin{array}{l}13 \mathrm{C} \\
(\% 0)\end{array}$ & $\begin{array}{c}\text { Años } \\
\text { Corregidos }\end{array}$ \\
\hline RG1 & $\| 2^{\underline{a}}$ & LATYR & LP- 291 & Carbón & $680 \pm 70$ & - & - & - \\
\hline RG1 & II $2^{\text {a }}$ & LATYR & LP- 238 & Carbón & $770 \pm 60$ & - & - & - \\
\hline RG1 & II $3^{a}$ & LATYR & LP- 284 & Carbón & $1110 \pm 100$ & - & - & - \\
\hline RG1 & II $4^{a}$ & LATYR & LP- 70 & Carbón & $980 \pm 70$ & - & - & - \\
\hline RG 6 & I 1 & UGA & UGA 7527 & Carbón & $80 \pm 70$ & 120 & $-22,50$ & +40 \\
\hline RG 6 & II $4^{-a}$ & UGA & UGA 7528 & Carbón & $420 \pm 70$ & 700 & $-23,47$ & +25 \\
\hline RG 6 & III 2aㅡ & UGA & UGA 7529 & Carbón & $670 \pm 100$ & 440 & $-23,56$ & +23 \\
\hline RG 6 & IV $4 \underline{a}$ & UGA & UGA 7530 & Carbón & $1120 \pm 110$ & 1170 & $-22,16$ & +46 \\
\hline Ty & $\mathrm{I}(\mathrm{I})$ & GIF & GIF 7910 & Carbón & $550 \pm 50$ & - & - & - \\
\hline Ty & la & GIF & GIF 7911 & Carbón & $570 \pm 50$ & - & - & - \\
\hline Ty & lb & GIF & GIF 7932 & Madera & $650 \pm 60$ & - & - & - \\
\hline Ty & IFondo & GIF & GIF 7934 & Cabello & $680 \pm 60$ & - & - & - \\
\hline Ty & II Exterior & GIF & GIF 7635 & Cuero & $820 \pm 60$ & - & - & - \\
\hline Ty & Ila & GIF & GIF 7912 & Carbón & $750 \pm 50$ & - & - & - \\
\hline Ty & Il b & GIF & GIF 7913 & Carbón & $790 \pm 50$ & - & - & - \\
\hline Ty & II b & GIF & GIF 9125 & Carbón & $980 \pm 30$ & - & - & - \\
\hline Ty & II b & GIF & GIF 9124 & Carbón & $1010 \pm 60$ & - & - & - \\
\hline Ty & II b & GIF & GIF 7633 & Carbón & $1020 \pm 60$ & - & - & - \\
\hline Ty & II C & GIF & GIF 9121 & Carbón & $890 \pm 50$ & - & - & - \\
\hline Ty & $\| \mathrm{C}$ & GIF & GIF 8709 & Carbón & $950 \pm 50$ & - & - & - \\
\hline Ty & II C & GIF & GIF 9123 & Carbón & $990 \pm 50$ & - & - & - \\
\hline
\end{tabular}

Tabla 1. Detalle de fechas para los sitios considerados en años C14, en aquellos casos en que se disponía del dato se incluyó el valor corregido por C13. Referencias Laboratoris: LP: LATYR (Laboratorio de Tritio y Radiocarbono, la Plata, Argentina); UGA: Center for Applied Isotope Studies (University of Georgia, USA); GIF: Centre des Faibles Radioactivités Laboratoire mixte CNRS-CEA. 
En la superficie del sitio se ha observado abundante material lítico y en muy escasa proporción, material cerámico. Las excavaciones, efectuadas por decapage, cubrieron una superficie de $7 \mathrm{~m}^{2}$ y mostraron una estratigrafía de tres capas naturales.

Las tareas de excavación pusieron en evidencia una serie de eventos de ocupación superpuestos. Se encuentran vestigios de camadas de gramíneas, no muy extensas, y restos de estructuras de combustión de pequeño tamaño. Asimismo, a unos $3 \mathrm{~m}$ de la pared del alero, se halló una línea de piedras de factura artificial que parece parte de un recinto. Se asume que este no debió ser el único construido a lo largo de la ocupación del sitio. De hecho, en el primer relevamiento se identificaron dos líneas artificiales de piedra, una de las cuales incluía un antiguo mortero lítico.

Las dataciones radiocarbónicas disponibles (Tabla 1) permiten situar las ocupaciones del sitio entre ca. 1110 y 680 años $A P$, es decir un lapso cronológico que abarca desde épocas formativas finales hasta momentos tempranos del período Tardío. Cabe destacar que por debajo del fechado más temprano existe aún sedimento fértil.

La hipótesis apunta a que se trataba de un "puesto" (Puesto de caza/pastoreo de altura; sensu Olivera 1997) constituido por varios recintos de diferente funcionalidad, de ocupación no permanente y asociado especialmente a actividades de caza y pastoreo. Es posible que la compleja estructura del sitio incluyera corrales, tal como ocurre en los puestos actuales y como parece haber observado Yacobaccio en Susques (Puna de Jujuy) en el sitio Puesto Demetria. De hecho, algunos de los fechados de ambos sitios son altamente coincidentes (RG1: $680 \pm 70$ y $770 \pm$ 60 años AP; PD: $760 \pm 70$ años AP) (Olivera y Elkin 1994; Yacobaccio et al. 1994).

El registro de excavación tiende a confirmar la hipótesis propuesta, ya que ofreció una interesante muestra de material lítico y arqueofaunístico, pero sólo unos pocos fragmentos de cerámica ordinaria (Olivera 1991).

En cuanto al material lítico, sobre un total de 99 instrumentos y núcleos, se destaca la alta presencia de puntas de proyectil y preformas $(32,4 \%)$, casi todas sobre obsidiana, similares a las de Casa Chávez Montículos, Base Residencial ubicada en el fondo de cuenca (3.450 msnm), aunque aquí aumentan las puntas apedunculadas asociadas a momentos tardíos del Formativo y algunas parecen corresponder a tipos del Tardío. Entre los desechos abundan micro e hipermicrolascas, siendo casi inexistentes las lascas para formas base. Esto, sumado ha signos de reactivación en las puntas de proyectil, permite concluir que esta actividad parece haber dominado por sobre la de la manufactura de puntas en el sitios (Escola 1999).

Finalmente, se obtuvo una interesante muestra arqueofaunística donde dominan absolutamente elementos óseos de la Familia Camelidae, con escasa presencia de otras especies entre la que se destacan roedores.

\section{Real Grande 6 (RG6)}

El sitio aprovecha una cueva con alero, de muy buena protección, ubicados en las cercanías de la margen izquierda del río Las Pitas, a una distancia de $1 \mathrm{~km}$ del sitio Real Grande 1. Las investigaciones en curso señalan la existencia de una alta similitud con este último sitio siendo probable un patrón de ocupación temporaria, dominando tareas relacionadas con la caza y el pastoreo de camélidos (Olivera 2006)

Las tareas de excavación, iniciadas en 1996, mostraron una estratigrafía de cuatro capas naturales las cuales fueron excavadas en varias extracciones de $0.05 \mathrm{~m}$, dependiendo su número de la potencia evidenciada por la capa natural. Los fechados radiocarbónicos disponibles hasta el momento (Tabla 1) ubican las ocupaciones del sitio en un lapso similar al de RG1 (ca. 1200-500 años $A P)$, con ocupaciones finales históricas y subactuales.

El registro artefactual hallado en este sitio, -lítico, fauna y en menor medida cerámica- se encuentra en proceso de análisis. Si bien es posible distinguir inicialmente algunas diferencias con RG1, siendo lo más destacado la mayor abundancia de cerámica que incluye fragmentos decorados de tipo Formativo y Tardío, la dominancia de los camélidos en el registro coincide con el otro alero.

\section{Alero Tomayoc (Ty)}

El sitio Tomayoc aprovecha un pequeño abrigo ubicado a 4170 msnm sobre la veritente oriental de la Sierra del Aguilar. El sitio fue estudiado entre 1987 y 1990 (Lavallée y García 1992, Lavallée et al. 1997), en relación con un proyecto mayor que investigaba las ocupaciones humanas prehistóricas y sus procesos de cambio cultural a escala regional. Los trabajos fueron realizados por el equipo dirigido por la Dra. Daniele Lavallée, integrado por investigadores del C.N.R.S. (Francia) y el Instituto de Ciencias Antropológicas de la Universidad de Buenos Aires (Argentina)

Las excavaciones realizadas en el interior y sobre el talud exterior del abrigo, en una superficie total de $50 \mathrm{~m}^{2}$, ofrecieron evidencias de una secuencia de ocupaciones humanas datadas por el método del C14 entre ca. 4250 y 550 años A.P., que han sido ordenadas en cuatro fases de ocupación en base a criterios cronológicos, estratigráficos y tipológicos (Lavallée et al. 1997). En este trabajo consideramos la Fase IV niveles I y II que corresponden a ocupaciones entre ca. 1000 a 550 años AP (Tabla 1).

La ocupación representada por los niveles I y II corresponde al Periodo Tardío, caracterizado por la instalación de aldeas permanentes en los valles y especialmente en la quebrada de Humauaca, donde se practicaba entonces 
una economía básicamente agrícola, complementada por el pastoreo de camélidos en sectores de más altura. En tal contexto, Tomayoc representa probablemente una instalación estacional ligada al pastoreo, quizás complementaria de una aldea permanente situada a cota inferior. Las ocupaciones en el alero fueron seguramente de corta duración (los niveles no presentan las características de una vivienda permanente) pero muchas veces repetidas, como lo demuestran la presencia de fogones complejos (intensamente utilizados y reacondicionados), como así también la cantidad de fogones simples.

La Fase IV muestra características diferentes de las anteriores, en especial por la existencia de una estructura circular artificial que cumplía funciones de habitación de actividades domésticas. Según los investigadores (Lavallè et al. 1997:21) resulta difícil fechar con precisión el inicio y fin de cada una de las ocupaciones, como también la duración de las interrupciones que las separan. La estructura habría sido construida alrededor de los 1020 años A.P., mientras el conjunto de las ocupaciones IV.2c y IV.2b, serían cercanas en el tiempo y habrían durado menos de un siglo con una interrupción de corta duración. Además, la interrupción entre IV.2b y IV.2a sería posterior a $790 \pm$ 50 años A.P. y el fin del funcionamiento de la construcción sería posterior a $750 \pm 50$ años A.P., aunque el alero se sigue utilizando hasta $550 \pm 50$ años A.P (Fase IV.1).

El alero nunca habría sido ocupado por largos períodos, sino utilizado para estadías relativamente cortas quizás como una etapa de circuitos caravaneros, lo cual se ve apoyado por el contexto de las ocupaciones (materias primas líticas de uso oportunístico, artefactos poco elaborados con excepción de las abundantes puntas de proyectil, escasa cerámica pero con presencia de tipos alóctonos, gran número de fogones con poco tiempo de uso) (Lavallè et al. 1997:30).

\section{Análisis Arqueofaunístico: comparación entre con- juntos}

\section{Controles tafonómicos}

En primer lugar, respecto a la integridad de las muestras, análisis efectuados sobre el material faunístico de los mencionados sitios, han determinado que en la meteorización de los conjuntos de Real Grande dominan los Estadíos 1-2 de Behrensmeyer (Tabla 2), lo que muestra que este proceso de perturbación no habría afectado significativamente la integridad de las mismas (Panebianco et al. 2005; Peña com. pers.). En cuanto a las alteraciones por otro tipo de agentes como raíces, carnívoros o roedores no presentan valores importantes. Las marcas de carnívoro son muy escasas (<0.5\%), lo que indica que este agente no parece haber incidido significativamente en la configuración de las muestras, algo similar a lo que ocurre con la acción de roedores que está por debajo del 6\% (ver Panebianco et al. 2005). Es de destacar que en todos los casos se han identificado epífisis, costillas y otras partes de baja densidad lo que parece corroborar las afirmaciones anteriores.

La preservación de los conjuntos tampoco parece haberse visto afectada por la densidad global ósea, ya que en todos los casos el rho de Spearman entre los valores de densidad mineral ósea obtenidos por Elkin (1995) para camélidos y el \%MAU de los conjuntos dieron un coeficiente de correlación bajo y no significativo $r s=0,06(p>$ $0,05)$ para el caso de RG1 y rs $=0,33(p>0,05)$ para RG6.

Asimismo, es importante destacar que los conjuntos faunísticos muestran índices altos de fragmentación (Panebianco et al. 2005), considerando que la relación entre NISP de enteros versus total de astillas no superan en ningún caso el 0,05\% lo que repercutió en los niveles de identificación de los mismos.

El panorama en Alero Tomayoc, resumido en la Figura 2 y Tabla 2, es bastante diferente y variado según el nivel estratigráfico considerado. El análisis realizado por Olivera y Grana (2005) permite obtener algunas observaciones interesantes.

Los grados de meteorización son muy variables lo que parece deberse a diferencias en el tiempo de exposición previa al enterramiento, pero también a diferentes condiciones del ambiente. La incidencia de carnívoros y roedores, también variables, mostrarían diferencias de acceso de estos animales a los huesos, relacionadas con los tiempos de permanencia y periodicidad de ocupación de los humanos durante las diferentes fases. Las raíces muestran tendencias similares que también tienen que ver con el uso o no de la estructura y la humedad del ambiente (Olivera y Grana 2005).

Se puede argumentar, de manera general, que las ocupaciones del Nivel I se desarrollaron a cielo abierto, sin otra protección que la que naturalmente ofrecía el alero. Esto permite plantear la hipótesis de que estamos frente a una sucesión de ocupaciones más bien eventuales, de corta duración, pero cercanas entre sí y sucesivas durante cierto lapso de tiempo, lo cual sería coincidente con las observaciones generales realizadas por los investigadores que analizaron el resto del contexto (Lavallée et al. 1997: 28-29).

Por otra parte, se puede sostener la hipótesis de que las ocupaciones del Nivel II a y b fueron eventos periódicos más estables y cercanos en el tiempo que aquellas que corresponden a los Niveles superiores ( $\mathrm{l}$ a, b y Fondo). Esto puede sugerir que durante el proceso Tardío en la región se produjeron modificaciones en la logística de los grupos humanos y que el alero refleja en alguna medida estos cambios en el sistema de asentamiento, en las estrategias de movilidad y/o uso del espacio por parte de esas sociedades Tardías.

La correlación estadística entre los valores de MAU de los conjuntos y los de densidad ósea estándar para camélidos 


\begin{tabular}{|c|c|c|c|c|c|c|c|c|c|c|c|c|}
\hline \multirow[b]{2}{*}{ Sitios } & \multicolumn{10}{|c|}{ METEORIZACION } & \multicolumn{2}{|c|}{ TOTAL } \\
\hline & 0 & $\%$ & 1 & $\%$ & 2 & $\%$ & 3 & $\%$ & 4 & $\%$ & $\mathrm{n}$ & $\%$ \\
\hline RG 6 & 0 & 0,0 & 102 & 11,4 & 651 & 72,7 & 136 & 15,2 & 7 & 0,8 & 896 & 100,0 \\
\hline RG 1 & 8 & 3,7 & 61 & 27,8 & 88 & 40,2 & 51 & 23,3 & 11 & 5,0 & 219 & 100,0 \\
\hline Ty I & 0 & 0,0 & 79 & 8,9 & 398 & 44,9 & 331 & 37,3 & 79 & 8,9 & 887 & 100,0 \\
\hline Ty II & 16 & 1,8 & 105 & 11,8 & 463 & 52,2 & 281 & 31,6 & 23 & 2,6 & 888 & 100,0 \\
\hline
\end{tabular}

Tabla 2. Proporciones de estadios de meteorización en los sitios considerados RG 1 y 6: Real Grande 1 y 6; Ty I y II: Alero Tomayoc Niveles I y II

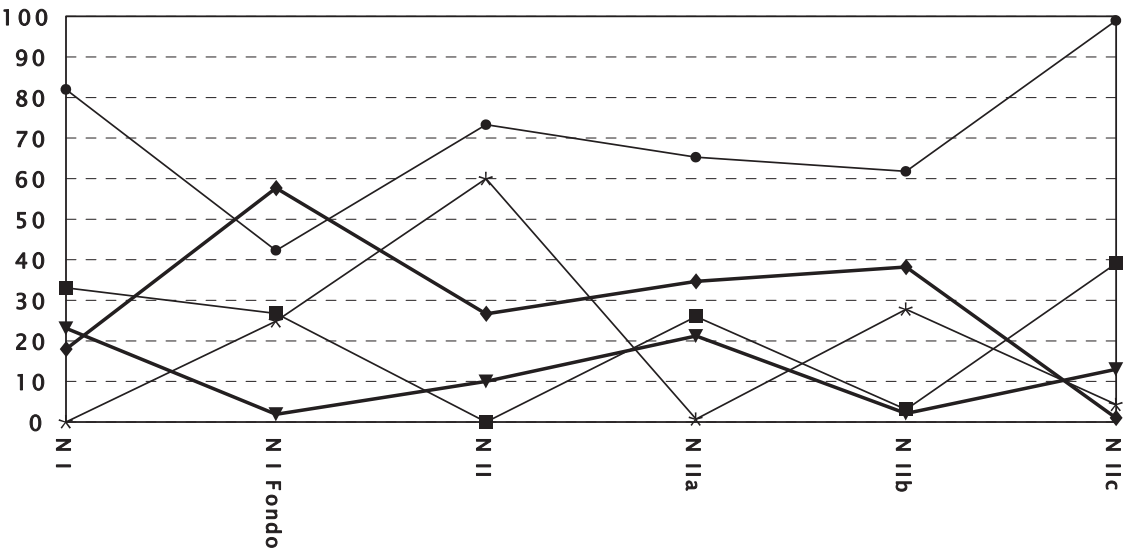

Niveles Estratigráficos

- ESTADIO 1-2 -ESTADIO 3-5 * Raices *Carnivor o-Roedor

Relación Meteorización y Agentes Naturales en \% NISP por niveles de extracción

Figura 2. Taxón Camelidae, sitio Alero Tomayoc (Tomado de Olivera y Grana 2005).

(Elkin 1995) muestra valores de correlación medio-bajo y estadísticamente no significativos ( $\mathrm{N}$ : $\mathrm{rs}=0,36 \mathrm{p}>0,05$; $\mathrm{N}$ II: $r s=0,45 p>0,05)$. Los valores no parecen constituir un factor de riesgo que represente destrucción parcial o total de partes esqueletarias selectivamente. Esto se refuerza por el hecho de que existen numerosos huesos de epífisis y otros sectores de baja densidad en todos los conjuntos (Olivera y Grana 2005).

\section{Análisis taxonómico y económico}

En RG1 el análisis indicó una dominancia de camélidos (92\%) por sobre otras especies. Los otros taxones representados, todos en proporciones muy bajas, corresponden a vizcacha, roedores pequeños, aves, félido, cánido (probablemente zorro) y un par de fragmentos de hueso humano. De todos ellos solo la vizcacha presenta alguna evidencia de consumo por presencia de huellas de corte. El material analizado en este trabajo proviene de los niveles I y II.

Los estudios preliminares realizados por Josefina Peña sobre el material arqueofaunístico de RG6, indican que predominan los restos correspondientes a especies de camélidos $(93,3 \%)$ acompañados, en menor medida, por vestigios de aves $(0,2 \%)$, roedores $(4,6 \%)$ y cérvido $(1,9 \%)$ (Peña com. pers.). Los restos óseos de camélidos analizados aquí proceden de los niveles II, III y IV, fechados entre 1120 y 420 años A.P.

Los estudios iniciales de la arqueofauna del sitio Alero Tomayoc (Ty) fueron realizados por la Dra. Denise Pozzi-Escot, quién sistematizó la información taxonómica y obtuvo interesantes conclusiones respecto de la explotación de recursos animales por parte de los ocupantes del sitio a través del tiempo (Lavallée et al. 1997). Los análisis indican una presencia absolutamente dominante del taxón Artiodactyla, con una abrumadora presencia de la Familia Camelidae y escasa evidencia de Cervidae. Dentro de las muestras se agregan una escasa presencia de pequeños vertebrados, en especial vizcacha (Lagidium viscacia) y roedores pequeños. Asimismo, se detecta una cantidad poco significativa de AVES, algunas muy pequeñas cuyo origen puede ser tafonómico.

A partir de ahora solo consideraremos para el análisis las especies de camélidos, ya que parecen ser las únicas de relevancia destacada en la economía de los grupos. En la Tabla 3 se resumen los valores $n$ de las muestras analizadas y los índices correspondientes (Número de especímenes identificados o NISP; Número Mínimo de Elementos o MNE; Número de elementos enteros o N Enteros).

En cuanto a las partes esqueletarias presentes en RG1, se observan la mayoría de las partes esqueletarias pero con cierta predominancia de piezas de pobre rendimiento en carne, con la posible excepción de las escápulas, radioulnas y húmeros, lo que apunta a que en el sitio existió cierto predominio de las actividades de matanza y procesamiento por sobre las de consumo (Figura 3).

Los perfiles etarios permitieron determinar que para los neonatos aumentan las partes esqueletarias de buen rendimiento, mientras que para los juveniles/adultos se destacan más las partes pobres en rendimiento económico. Esto sugiere que ciertas partes no se consumieron 


\begin{tabular}{cccccc}
\hline SITIO & NIVEL & FASE & NISP & MNE & N ENTEROS \\
\hline RG1 & IIII & - & 219 & 166 & 86 \\
RG6 & II-II-IV & - & 971 & 461 & 108 \\
Alero Tomayoc & Nivel I & IV.1 & 888 & 374 & 85 \\
& Nivel II & IV.2 & 896 & 360 & 48 \\
\hline
\end{tabular}

Tabla 3. Muestras del Taxón Camelidae consideradas por sitio. Referencias: NISP, Número de Especímenes Identificados; MNE, Número Mínimo de Elementos Oseos.

en el lugar implicando el posible traslado de partes para su consumo diferido, privilegiándose en el sitio posiblemente el consumo de animales menores de un año (Olivera 1991).

Por su parte, RG6 (Figura 3) muestra un panorama similar al de RG1 aunque se acentúa el dominio del esqueleto apendicular sobre el axial. Aquí las escápulas y pelvis son muy escasas, también aparecen menos representadas las mandíbulas, maxilares y falanges. En cuanto a los perfiles etarios, si bien aún en proceso, muestran un definido dominio de los ejemplares adultos si nos guiamos por los estados de fusión. El panorama de proporciones del \%MAU es altamente coincidente con el de juveniles/ adultos de RG1, lo que refuerza la tendencia anterior. Es posible que ciertas partes se trasladaran fuera del sitio, aunque parece que en el mismo también existió consumo de animales de mayor edad.

En el Alero Tomayoc las proporciones de cada parte esqueletaria expresados en valores de \%MAU se volcaron en la Figura 4. Se puede observar que si bien existen algunas diferencias entre los niveles, los conjuntos muestran una cierta tendencia común donde predominan las partes correspondientes al esqueleto apendicular por sobre las del esqueleto axial. En este último están más representados huesos de la cabeza y el cuello y muy poco los de la columna vertebral, lo cual coincide con los sitios de Real Grande.

Por otra parte, los huesos de las patas delanteras y traseras están muy bien representados, con una menor proporción de las falanges. En algunos aspectos Ty se asemeja a los sitios de RG (predominancia del esqueleto apendicular sobre el axial), pero aquí la elevada proporción de algunas partes ricas en rendimiento de carne parecen apuntar a mayor consumo in situ.

La Dra. Pozzi-Escot (Lavallè et al. 1997) ya había hecho notar que los individuos juveniles mantienen una cierta constancia de entre el 24 al 29\%, mientras los neonatos solo alcanzan entre el 13 y el $16 \%$ con excepción de un 34\% en el nivel IV.2c. Así, la proporción de animales maduros en $\mathrm{Ty}$, que promedia el $59 \%$ de adultos, es mucho más importante que en RG1 con un promedio de $16 \%$

En la Figura 5 se consideró la distribución de las Partes Esqueletarias Básicas expresadas en porcentaje de MNE, ya que estas pueden dar una idea más precisa que el MAU de las unidades de trozamiento.

Se puede observar que en las proporciones de PEB se acentúan las tendencias marcadas anteriormente. Es notable el aumento de costillas y patas en Tomayoc respecto de los sitios de Real Grande. En el resto de las partes se destaca una proporción más armoniosa de las falanges con los huesos del pie en Tomayoc, en especial respecto de RG1. Ya marcamos una mayor incidencia de la meteorización en Ty lo que puede haber incidido en la representación de cráneo, vértebras, escápulas y pelvis, huesos más proclives a grados de fracturación y deterioro que dificultan sus niveles de identificación (Olivera y Grana 2005). Sin embargo, en general, Tomayoc ofrece un panorama de mayor consumo y estabilidad en algunas de las ocupaciones que los sitios de Real Grande, lo cual coincidiría con el contexto general del sitio.

Se puede destacar que los perfiles descriptos (Figura 3, 4 y 5) parecen corresponder a determinadas prácticas antrópicas relacionadas con la toma de decisiones para

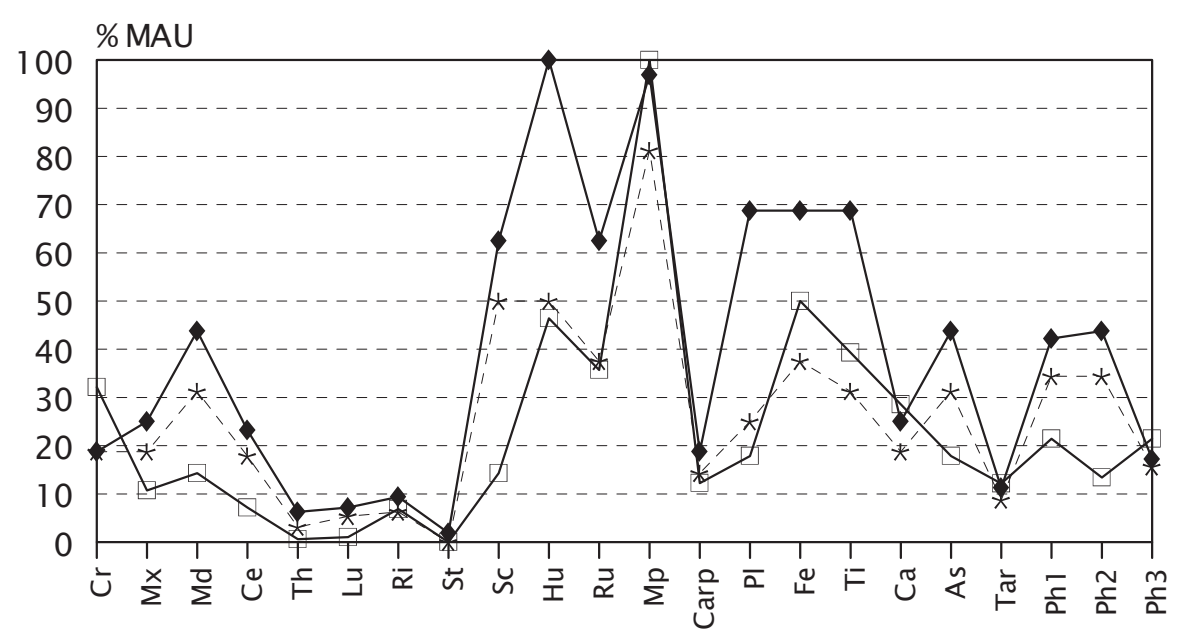

Parte Esqueletaria

$\star$ RG1 Conjunto * RG1 Juvenil/adulto - RG6 Conjunto

Figura 3. Taxón Lama sp., sitio Real Grande 1 (I-II) y 6 (II a IV). MAU\% en RG6 y relación entre MAU\% total vs. juvenil/adulto en RG1. 


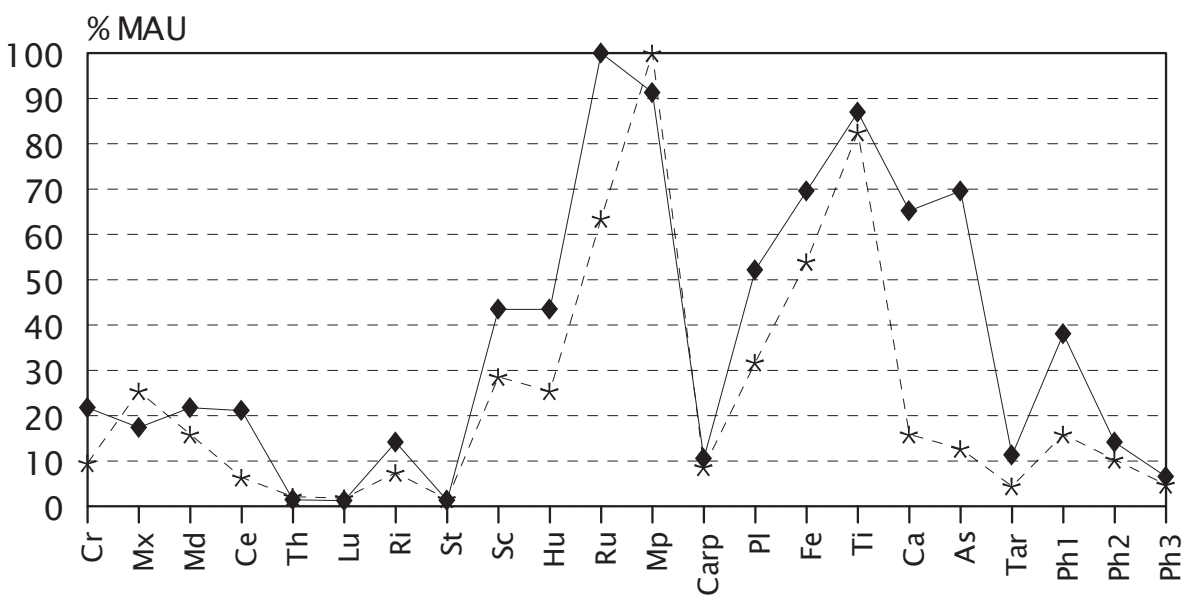

Parte Esqueletaria

- Nivel 1 * Nivel 2

Figura 4. Taxón Lama sp., sitio Alero Tomayoc (Niveles 1 y 2). MAU\% total niveles 1 y 2.

el procesamiento y consumo de los animales, más que con problemas tafonómicos y post-depositacionales que hayan originado una alta desaparición diferencial de ciertas partes. Así, dentro de un panorama similar de los tres sitios, el de la Puna Norte parece haber cumplido un rol algo diferente dentro de la dinámica de asentamiento de los grupos humanos del Tardío.

Para sumar contrastación a las hipótesis y tendencias planteadas apelamos al análisis osteométrico, el cual contribuye a distinguir entre las especies domesticadas y silvestres. Este hecho, fundamental para analizar las estrategias de pastoreo y caza, también permite obtener información relacionada con la funcionalidad de los sitios y la logística de los grupos humanos que los ocuparon.

\section{Osteometría}

En la actualidad se reconocen cuatro especies formando

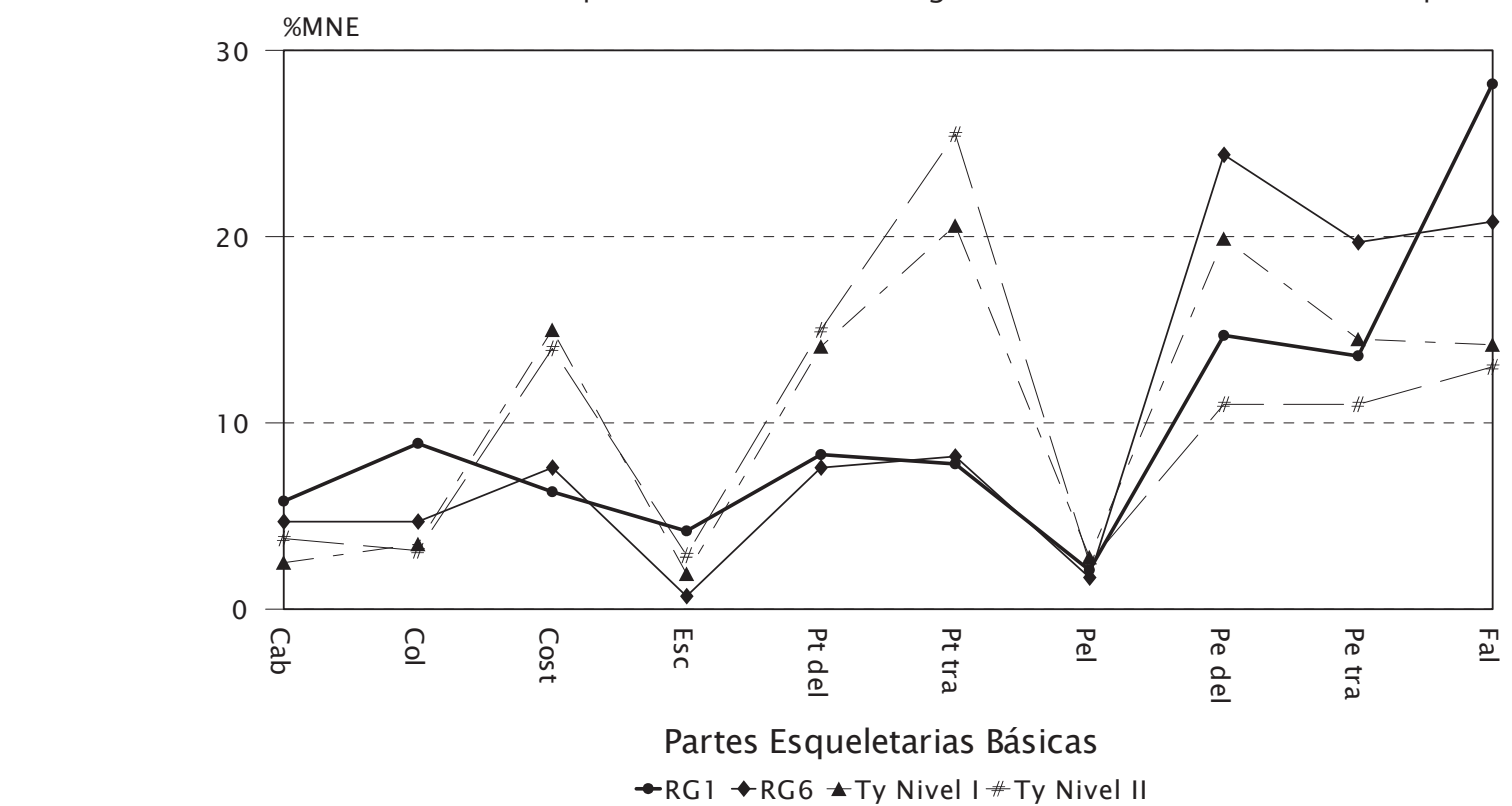

parte de la familia Camelidae en sudamérica: dos especies silvestres, Lama guanicoe (guanaco) y Vicugna vicugna (vicuña); y dos domésticas, Lama glama (llama) y Lama pacos (alpaca). Cuando estas especies son comparadas, un aspecto que sobresale es la diferencia significativa que exhiben en su tamaño corporal, pudiendo ser ordenadas de acuerdo a un gradiente que -en los Andes Centro Sur- va desde la llama de mayor tamaño, pasando por el guanaco, la alpaca y finalmente la vicuña de menor tamaño (Elkin et al. 1991, Mengoni y Yacobaccio 2006). Estas diferencias de tamaño son las que permiten usar caracteres ostoemétricos para diferenciar entre cada una de las especies, distinguiendo en el proceso entre formas silvestres y domesticadas.

En el presente trabajo, los elementos óseos medidos corresponden a primera falange y metapodio. Estos han sido seleccionados teniendo en cuenta que, por lo general, la identificación ínter-especifica de restos

Figura 5. Taxón Camelidae, sitios Real Grande 1, Real Grande 6 y Alero Tomayoc. Representación de Partes Esqueletales Básicas expresadas en MNE\%. 
de camélidos para la región andina se ha realizado a partir de estudios osteométricos realizados sobre dichos elementos, los cuales habitualmente presentan buena conservación y tienen un aceptable valor discriminante (Izeta 2004, Miller y Burger 1995, Yacobaccio et al. 1997-1998). En la Tabla 4 se detallan los totales de huesos medidos en cada sitio.

Se seleccionaron sólo los huesos con fusión completa, que presentaran un buen estado de conservación, que no mostraran una alteración superior al estadio de quemado y que presentaran los puntos de medición necesarios para este tipo de análisis (Elkin et al. 1991, von den Driesch 1976).

Cada elemento analizado fue medido siguiendo los criterios definidos por Kent (1982), Menegaz y colaboradores (1988), von den Driesch (1976), Wing (1972) y resumidos en una lista elaborada por Elkin (1996) y Mengoni Goñalons (com. pers.). En cuanto al registro de las variables se utilizó como herramienta de medición un calibre Vernier (precisión 0,02) y los datos fueron registrados en $\mathrm{mm}$.

Los datos métricos de los taxones de referencia fueron obtenidos de diferentes fuentes (Izeta 2004 y com. pers., Mengoni Goñalons com. pers., Elkin 1996, Belotti López de Medina 2007, Yacobaccio com. pers.) y de resultados nuevos producto de mediciones realizadas en llamas actuales del área de Antofagasta de la Sierra. Los animales de referencia corresponden a: 2 guanacos andinos, 9 llamas y 6 vicuñas de diferentes áreas del noroeste argentino (Tabla 5).

Sobre las mediciones que constituyen nuestra muestra se aplicaron los siguientes análisis: Técnica de distancia de logaritmos de Meadow (1987) y Análisis de Conglomerados usando el UPGMA (Unweighted Pair Group Using Arithnetical Averages). Para la aplicación de esta última técnica, las falanges han sido discriminadas previamente en delanteras y traseras basándonos en la caracterización morfológica propuesta por Kent (1982: 164-166). La totalidad de los análisis multivariados se realizaron con la versión 6.0 de la aplicación Statistica, de Stastsoft Inc.

Se decidió aplicar ambas técnicas puesto que estudios previos demostraron que las mismas pueden usarse de manera complementaria y que la verificación de un método osteométrico por el otro permite otorgarle a cada uno un mayor grado de confiabilidad en las asignaciones taxonómicas que si se utilizan de manera aislada (Grant 2009).

\section{Resultados osteométricos}

La aplicación de las técnicas mencionadas dio como resultado varios gráficos que se discutirán a continuación.

\section{Falanges proximales}

Tal como se observa en la Figura 5, los datos métricos del ancho máximo de la superficie articular proximal de falanges primeras obtenidos de un total de 27 elementos, que fueron comparados con el estándar de guanaco actual a través de la diferencia de logaritmos. La medida estándar a partir de la cual se comparó cada elemento está representada gráficamente como la línea 0 . Los valores más alejados hacia la izquierda son más pequeños que el estándar de guanaco, por lo que podrían ser interpretados como vicuñas, mientras que los más alejados hacia la derecha son más grandes, por lo que podrían ser asignados a llamas (Elkin 1996). Sin embargo, existen valores que oscilan entre $\pm 0,02$, los cuales son bastante aproximados al guanaco de referencia pero que también podrían superponerse con los de las llamas de menor tamaño. En estos casos, siguiendo a López (2003), se prefirió asignar a los especímenes a la categoría de "llama-guanaco" para expresar el rango en que los valores se superponen (López 2003).

En la construcción de la figura, se han agrupados los especímenes provenientes de los sitios Real Grande 1 y 6 por un lado y los de Alero Tomayoc por el otro, con el objetivo de comparar las tendencias en cuanto a la identificación de especies de camélidos entre los mismos. Las barras representan la frecuencia absoluta para cada categoría de tamaño y cada celda representa una medición individual, correspondiendo los números dentro de estas últimas al espécimen arqueológico medido. La rotulación de las celdas en las figuras permitió la comparación de los resultados obtenidos mediante la técnica de Meadow con los resultados de la aplicación de las técnicas estadísticas multivariadas.

En los sitios Real Grande 1 y 6, y siguiendo las tendencias descriptas en trabajos previos (Grant 2009, Olivera y Grant 2009), se observa un predominio absoluto de especímenes correspondientes a camélidos pequeños asociados a estándares de vicuña (Vicugna vicugna) (Figura 6). De esta manera, de 18 especímenes analizados para estos sitios, el $100 \%$ ha sido identificado por osteometría como correspondiendo a vicuña.

Por otro lado, en el Alero Tomayoc se observa un mayor rango de variabilidad pudiendo ser agrupado en diferen-

\begin{tabular}{|c|c|c|c|c|c|}
\hline Elementos & Sitios & Real Grande 1 & Real Grande 6 & Alero Tomayoc & Total \\
\hline Falange Proximal & & 10 & 8 & 9 & 27 \\
\hline Metapodio Distal & & 13 & 5 & 11 & 29 \\
\hline Total & & 23 & 13 & 20 & 48 \\
\hline
\end{tabular}

Tabla 4. Muestra de elementos analizados para cada sitio. 


\begin{tabular}{lll}
\hline Código & Especímenes de referencia & Fuente \\
\hline V 999 & V. vicugna & Izeta 2004 \\
V 600 & V. vicugna & Yacobaccio et al 1997-1998 \\
V 650 & V. vicugna & Yacobaccio et al. 1997-1998 \\
L 148 & L. glama & Izeta 2004 \\
L 200 & L. glama & Comparativa (P. Antofagasta de la Sierra, INAPL) \\
L 151 & L. glama & Izeta com. pers. \\
L 150 & L. glama & Izeta com. pers. \\
L 550 & L. glama & Yacobaccio com. pers. \\
L 450 & L. glama & Yacobaccio com. pers. \\
G 149 & L. guanicoe & Izeta 2004 \\
G 350 & L. guanicoe & Mengoni Goñalons com. pers. \\
\hline
\end{tabular}

Tabla 5. Códigos de ejemplares de referencia empleados en los análisis multivariados.

tes categorías de tamaño. A la izquierda de la figura se encuentra un grupo compuesto por cinco especímenes más pequeños que el estándar de guanaco actual, asignados a vicuña ${ }^{1}$. Se observa también un ejemplar cuyo valor se distribuye alrededor del estándar de guanaco moderno por lo que, como hemos mencionado previamente, podría tratarse tanto de guanaco como de llama pequeña. A la derecha de la figura, se encuentra un tercer grupo compuesto por tres falanges más grandes que el estándar, siendo asignados a llamas.

Para la aplicación de los análisis de agrupamiento sobre falanges primeras se utilizaron cinco caracteres morfométricos del miembro delantero y posterior y dos caracteres de ambos miembros tomados en conjunto, ya que para este caso los especímenes arqueológicos se encontraban fragmentados en sus porciones distales, imposibilitando su discriminación. En los tres casos los resultados del UPGMA se expresan en forma de dendrograma, volcados a las Figuras 7, 8 y 9.

En la Figura 7 se pude observar que para el miembro posterior hay dos grupos principales que coinciden con

1 La presencia de alpaca (Lama pacos) en el Noroeste Argentino prehispánico no ha sido aún documentada fehacientemente. Las condiciones ambientales (ausencia de típicos "bofedales" de altura con suelos saturados de humedad) no facilita el desarrollo de esta especie doméstica. En Ty fueron identificados dos dientes incisivos que se asociaron a alpaca (Lavallée et al. 1997), pero no existen evidencias osteométricos que indiquen elementos de esta especie. las categorías de camélidos pequeños y grandes. Dentro del grupo de los pequeños se observa el agrupamiento de ocho especímenes de los sitios Real Grande 1 y 6 y tres del sitio Alero Tomayoc junto con las falanges comparativas de $V$. vicugna. Por otro lado, en el grupo de camélidos grandes el espécimen TOM002 del Alero Tomayoc forma un grupo definido junto con falanges comparativas correspondientes a guanaco andino, más específicamente con el ejemplar proveniente de la falda occidental del Aconquija (Izeta 2004). Se trata del mismo espécimen que con la técnica de distancia de logaritmos se ubicaba cercano al estándar de guanaco y que fue agrupado en la categoría de llama-guanaco. De esta manera, los análisis multivariados, al incluir un mayor número de caracteres por elemento y de individuos de referencia, permitió ajustar a una resolución de grano más fino los resultados obtenidos por la técnica anterior, refinando la identificación interespecífica.

Para el miembro anterior también se produce la discriminación entre camélidos grandes y pequeños de manera muy clara (Figura 8). En el caso del grupo pequeño se observa la presencia de tres ejemplares de los sitios Real Grande 1 y 6, correspondiendo al morfotipo vicuña. Para el grupo grande podemos ver el agrupamiento del espécimen arqueológico TOM001 de Tomayoc junto con cuatro falanges anteriores correspondientes a un ejemplar de referencia de llama proveniente del área de Antofagasta de la sierra. Este resultado coincide con el

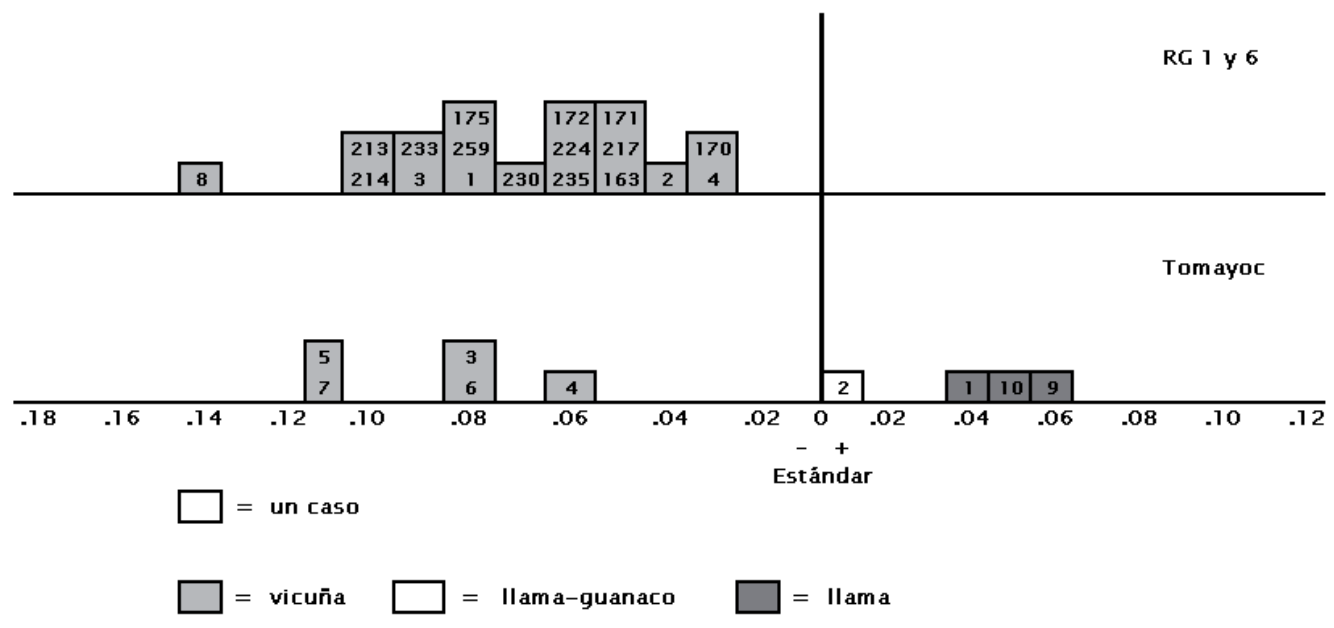

Figura 6. Comparación de los valores osteométricos para falanges primeras de los sitios RG 1 y 6 y Ty (Técnica de Meadow). 
obtenido mediante la aplicación de la técnica de Meadow.

Por ultimo, al observarse el grafico resultante del análisis de agrupamiento para los 2 caracteres morfométricos de falanges delanteras y posteriores (Figura 9), se vuelve a apreciar la discriminación entre los dos grupos de camélidos aunque esta vez, debido probablemente a la menor cantidad de variables empleadas en el análisis, la formación de los grupos es menos definida que para los casos anteriores. Aún así, se observa que siete ejemplares provenientes de los sitios Real grande 1 y 6 y uno de Tomayoc forman un grupo junto con ejemplares de vicuña. Por otro lado, los ejemplares TOM010 y TOM009 se agrupan junto con un ejemplar de llama, confirmando de esta manera los resultados obtenidos de la implementación del la técnica de Meadow.

\section{Metapodios distales}

Como se observa en la Figura 10, los datos métricos del ancho máximo del extremo distal del metapodio obtenidos de un total de 29 elementos, que fueron comparados con el estándar de guanaco actual a través de la diferencia de logaritmos. En concordancia con los resultados obtenidos para las falanges, la totalidad de los ejemplares de los sitos Real Grande 1 y 6 ha sido identificada por esta técnica como correspondientes a vicuñas. Para el caso del Alero Tomayoc, se observa que, salvo la excepción de un espécimen, el resto de los metapodios muestran un tamaño más pequeño que el estándar de guanaco siendo asignados a vicuñas. Por su lado, el ejemplar $n^{\circ}$ 15 muestra un tamaño más grande que el estándar, correspondiendo a Lama glama.

Los análisis de conglomerados, confirman los resultados obtenidos mediante la técnica anterior, ya que 28 de los 29 metapodios se agrupan junto con ejemplares correspondientes a vicuña mientras que el ejemplar $n^{\circ} 15$ (TOM015) forma un grupo definido junto con un metapodio de llama dentro del grupo de camélidos grandes (Figura 11).

\section{Discusión y conclusiones.}

El análisis del registro desarrollado en las páginas anteriores aporta algunos elementos interesantes sobre el funcionamiento de los sitios de altura dentro de la logística de asentamiento y subsistencia de las poblaciones prehispánicas de la Puna durante el período Tardío.

En primer lugar, se debe destacar que si bien parece confirmarse que estos sitios son ocupados en forma no permanente durante el ciclo anual, su utilización es reiterada durante períodos relativamente prolongados a lo largo del tiempo, aunque pueden existir entre estos períodos discontinuidades de duración variable. Asimismo, la duración de las ocupaciones parece ser variada a lo largo del proceso durante el cual se los utilizó. Estos períodos pueden variar desde pocos días hasta, quizás, algunos meses en forma estacional o no si nos guiamos por los contextos arqueológicos y las informaciones actualísticas de la etnografía y la etnoarqueología.

En el caso de RG1 las ocupaciones parecen ser discretas y de corta duración, siendo claras las evidencias de consumo, aunque más importantes en el caso de animales menores a un año de edad, reservándose aparentemente los animales mayores procesados en el sitio para un consumo diferido. En cambio en Ty las estadías pudieron ser más prolongadas durante ciertos períodos de ocupación,

Single Linkage

City-block (Manhattan) distances

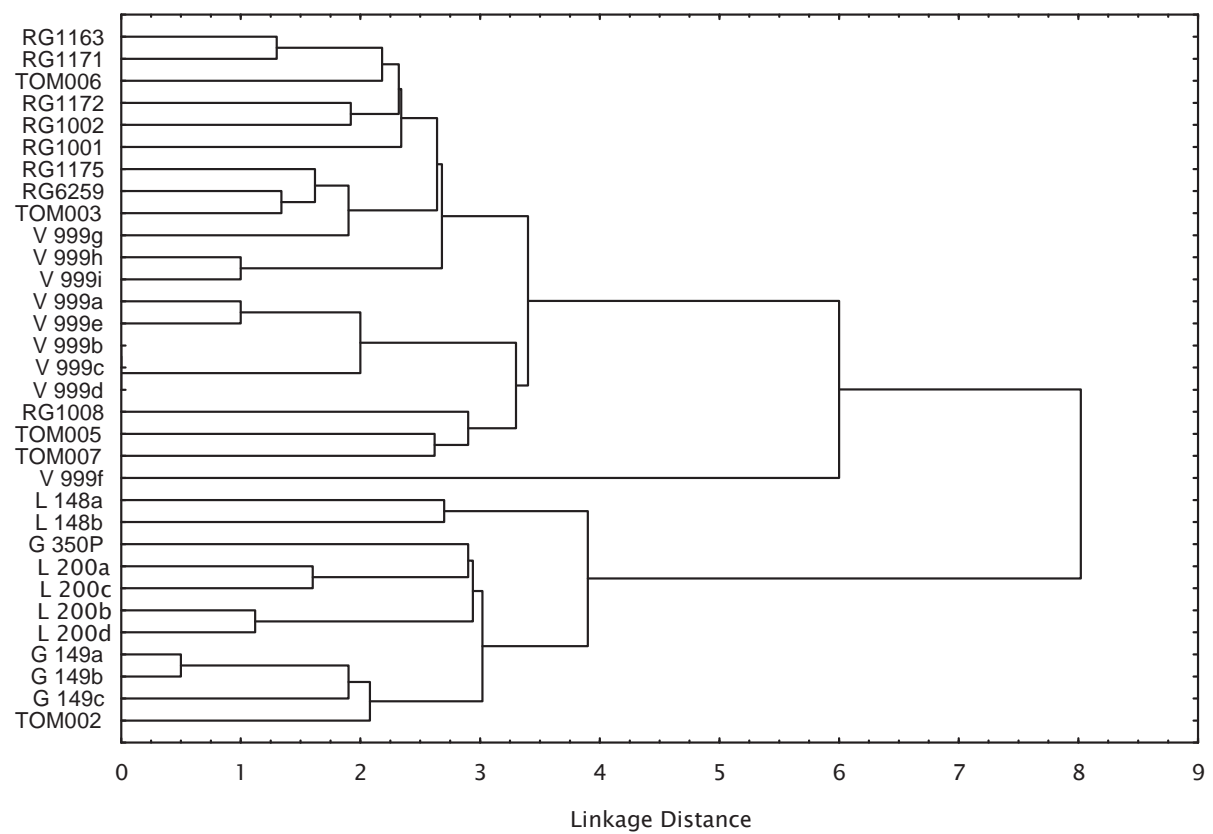

Figura 7. Dendrograma correspondiente a los resultados obtenidos de las mediciones de cinco caracteres morfométricos de falanges posteriores. 
Single Linkage

City-block (Manhattan) distances

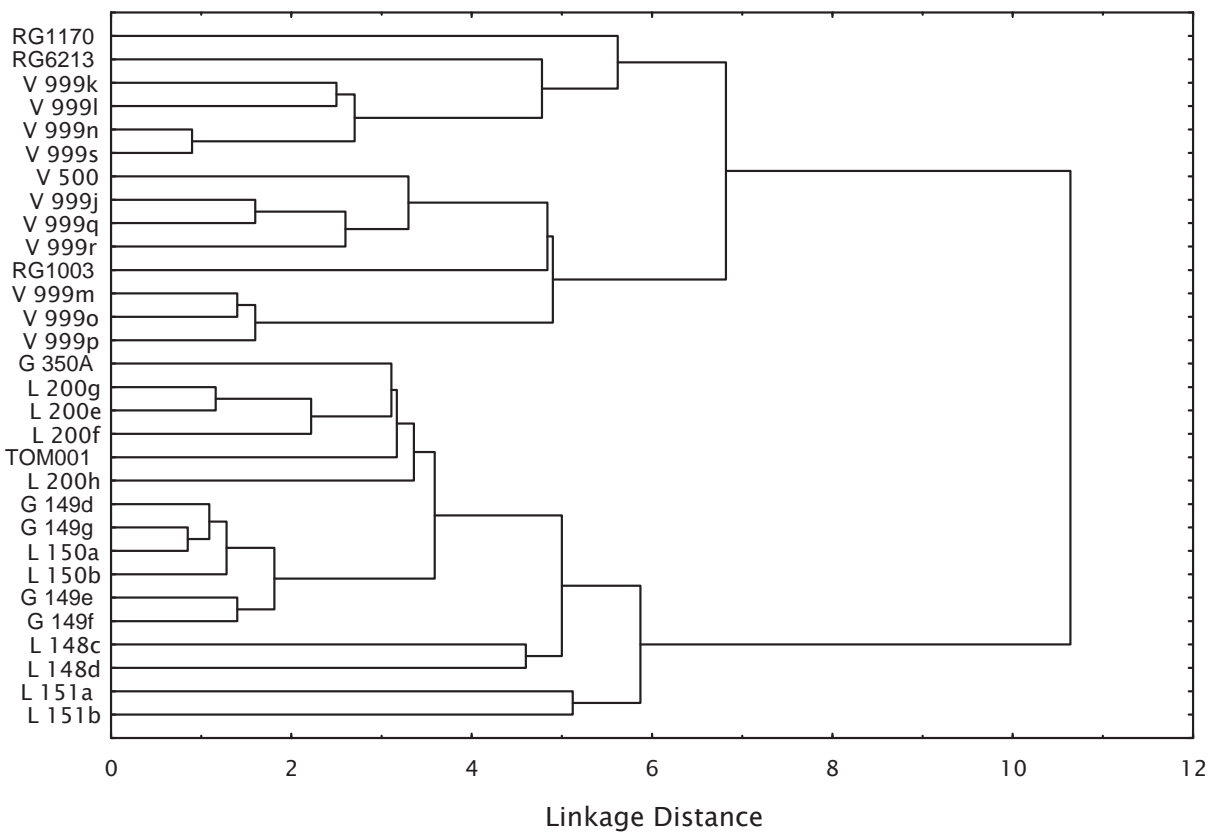

Figura 8. Dendrograma correspondiente a los resultados obtenidos de las mediciones de cinco caracteres morfométricos en falanges anteriores.

según la evidencia presentada por la representación de partes esqueletarias y otros elementos del contexto (mayor número de fogones, evidencias cerámicas y material lítico). Asimismo, la estructura de piedra altamente reutilizada de Ty puede estar apuntando en la misma dirección.

En RG6 algunas estancias parecen ser algo más prolongadas que en RG1, esto tomando en cuenta ciertos elementos de contexto (mayor cantidad de cerámica y mayor variabilidad de artefactos líticos). Sin embargo, la representatividad de las partes esqueletarias es similar en ambos sitios, así como la absoluta adscripción al estándar de vicuña en los huesos analizados osteométricamente.

Un detalle a tener en cuenta es que parece menor la presencia de neonatos y juveniles en RG6, esto puede estar alertando sobre cierta diversidad en la posición logística de este sitio respecto de RG1. Confiamos en que la profundización de las investigaciones puede traer mayor claridad a este problema.

Otro elemento interesante es que, más allá de las actividades específicas desarrolladas en los sitios, estos parecen formar parte de sistemas logísticos que incluyen otro tipo de asentamiento. Los mencionados asentamientos se ubicarían en cotas más bajas y, presumiblemente, sería Bases Residenciales de Actividades Múltiples y ocupación de año completo.

Respecto de las actividades económicas desarrolladas en los puestos de altura es evidente que estas están más limitadas a aquellas que tienen que ver con la obtención y manejo de recursos de subsistencia. Aunque no podemos descartar que en ciertos casos también se relacionen con la recolección de otro tipo de recursos como leña y materias primas líticas, las evidencias contextuales apuntan a que se priorizó la explotación y manejo del recurso Camelidae.

Los perfiles de los conjuntos muestran cierta selectividad de partes del esqueleto, donde las porciones apendiculares dominan ostensiblemente sobre la mayoría del esqueleto axial. La columna vertebral y las costillas están especialmente subrepresentadas en Real Grande, aunque en ciertas ocupaciones de Ty estas últimas parecen más abundantes. Esto puede tener que ver, como apuntáramos anteriormente, con alguna particularidad en los tiempos de ocupación y/o el funcionamiento del sitio, tema que luego retomaremos.

La caza de camélidos silvestres parece haber ocupado un lugar destacado y la vicuña ser la presa fundamental, aunque las evidencias de guanaco en Ty indican que en la Puna norte estos animales, quizás en menor medida, también fueron predados cuando se podía acceder a ellos. La ausencia de guanacos en los sitios de Real Grande puede obedecer a que estos animales no estaban disponibles en épocas Tardías en la cercanía del sitio, habiendo disminuido su número con el paso del tiempo y retrayéndose hacia cotas más altas. No habría sido igual en la Puna norte donde aún hoy hay evidencias de la especie en esos ecoambientes (ver en Wheeler 1991 un resumen de la distribución actual de la especie). En ese sentido, es muy interesante el aporte de la osteometría porque prácticamente no hay evidencias de la caza del guanaco para las poblaciones tardías y esto nos obligará a extremar los controles en el futuro para otras muestras de esta época. 
Single Linkage

City-block (Manhattan) distances

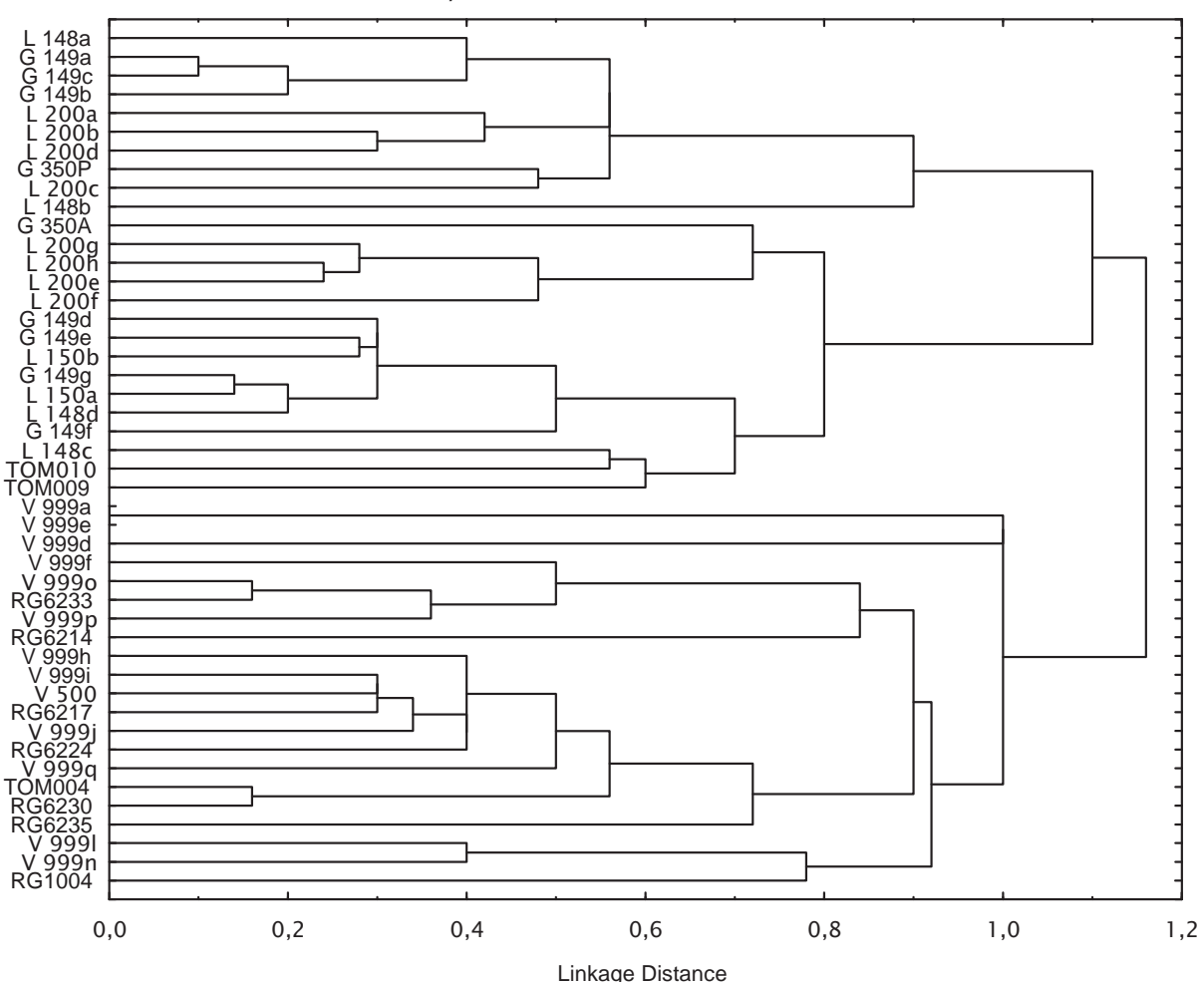

Figura 9. Dendrograma correspondiente a los resultados obtenidos de las mediciones de 2 caracteres morfométricos en falanges anteriores y posteriores (ancho de la superficie articular proximal y alto de la superficie articular proximal).

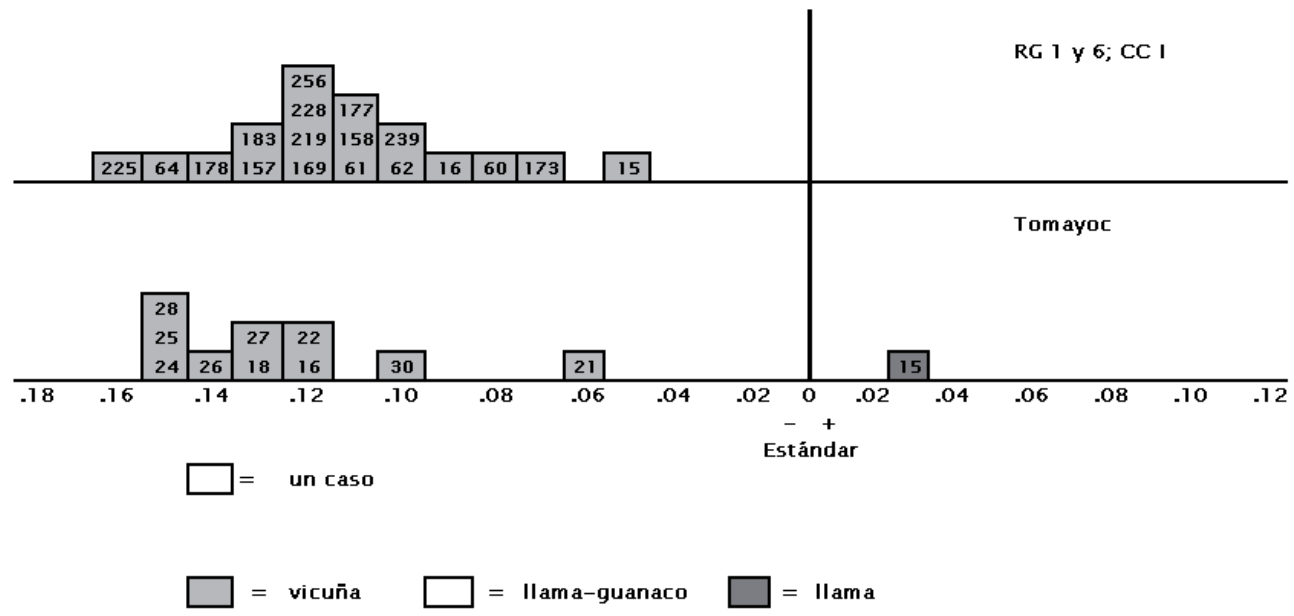

Figura 10. Comparación de los valores osteométricos para extremos distales de metapodios de los sitios RG 1 y 6 y Ty (Técnica de Meadow).

La alta presencia de puntas de proyectil en todos los sitios de Real Grande parece avalar la hipótesis de que la caza constituyó una actividad altamente importante. Asimismo, las evidencias de reactivación por sobre las de manufactura de puntas (en RG1 las puntas representan el $32,4 \%$ de los artefactos formalizados y el $47 \%$ de las mismas muestran signos de reactivación) apuntan tanto a que las estancias no eran muy prolongadas como que la actividad de manufactura lítica no era una función primordial de estos sitios.

Si bien se había planteado desde un modelo teórico que otra función importante de los puestos de altura era el pastoreo de rebaños domésticos de llamas durante el invierno (meses de abril a setiembre), esto se apoyaba en la Puna Sur básicamente a partir de registros etnográficos y etnoarqueológicos ya que todo el registro osteométrico de Real Grande se asocia a los estándares de vicuña. Nuevamente Ty viene a aportar datos interesantes ya que es evidente la presencia de animales que pueden asociarse a estándares de llama, si bien su número parece ser radicalmente menor que el de la especie silvestre en las tareas de procesamiento.

Actualmente, los pastores sacrifican pocos animales de rebaño en los puestos estacionales (Madero y Yacobaccio 1994) y lo mismo parece haber acontecido en el pasado. Este hecho resulta lógico en virtud de que durante el invierno los animales pierden peso y están más expuestos a los predadores. Así, se prefiere preservar las llamas 
Single Linkage

City-block (Manhattan) distances

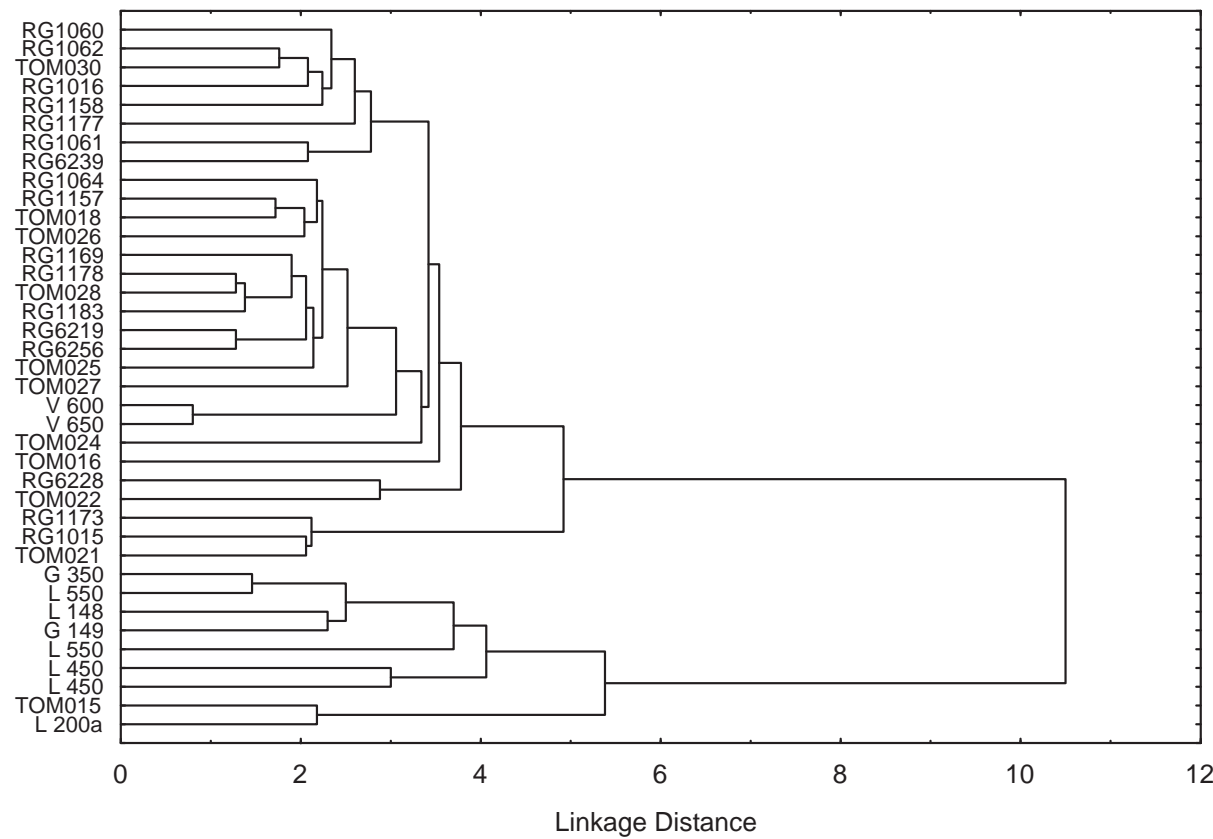

Figura 11. Dendrograma correspondiente a los resultados obtenidos de las mediciones de 5 caracteres morfométricos en metapodios distales.

que se deban sacrificar para los momentos de pastura de verano luego del engorde. Por supuesto que esto, como toda actividad humana, constituye lo más común pero no cubre las numerosas excepciones que obedecen a situaciones particulares.

Asimismo, la presencia de llamas no constituye una evidencia absoluta de que se trate solo de puestos de caza/ pastoreo. También, alerta sobre la posibilidad de que estos sitios hayan jugado un rol más amplio y complejo dentro de la logística de los grupos humanos constituyendo, por ejemplo, posibles estaciones de caravaneo como se ha propuesto para Ty (Lavallée et al. 1997).

El sensible aumento de animales adultos en las grandes aldeas del Tardío y la conformación general de los perfiles erarios, morfométricos y de fibra apuntan a un manejo orientado a producir animales más especializados que el morfotipo de llama intermedia generalizado en el Formativo (Grant 2008, Olivera 1997, Reigadas 2008). Así, grupos de rebaño especializados en la carga (caravaneo institucionalizado) y la obtención de fibra (producción textil) se habrían desarrollado cada vez con mayor eficiencia a partir de ca. 1200-1300 años AP. Por otro lado, ¿la posible presencia de alpaca en Ty no estará relacionada con la introducción de esos animales para su explotación textil o para la producción de híbridos con llama para la producción de fibra de comprobada mejor calidad en cantidades importantes? Asimismo, la explotación de los animales silvestres no puede asociarse unidireccionalemente a la provisión de carne para alimento, no solo es factible la utilización de la fibra y los cueros sino también la producción de elementos de intercambio. Por supuesto que estas hipótesis requerirán de mayores registros en el futuro, pero son indudablemente excitantes por sus implicaciones.
También, se debe destacar que la absoluta dominancia de Camelidae en las muestras (más del 90\%) y la variedad de especies silvestres y domesticadas, no implican que la carne tenga igual predominio en la dieta de los grupos. De igual modo, a pesar que las vicuñas están cuantitativamente más representadas que las Ilamas, no se puede afirmar para estos momentos cual era el grado de relevancia relativa de la caza y el pastoreo en el sistema económico de los grupos. Como adelantáramos, es posible que la dominante presencia de vicuña en los puestos de altura obedezca a decisiones logísticas donde se reservaban las llamas para ser sacrificadas en las bases residenciales permanentes.

En este sentido, también debe tenerse en cuenta que la existencia de una estrategia predominante como la agricultura, el pastoreo o una combinación de ambos, no implica que la incidencia del aporte productivo a la dieta sea dominante. Lo que sí se puede esperar, es que la incorporación de nuevas estrategias agrícola-ganaderas traiga aparejado cambios organizacionales internos en el sistema cultural que se reflejarían en el sistema de asentamiento-subsistencia del grupo (Olivera 2006). De esta manera, si bien es probable que la caza haya contribuido de manera fundamental a la dieta y economía de los grupos, es necesario relacionar los datos obtenidos en cuanto a la frecuencia relativa de animales silvestres y domesticados en los distintos tipos de sitios, con la información existente respecto a las características organizacionales particulares de las sociedades analizadas (Grant 2008). A una conclusión parecida arriba Mengoni Goñalons en su análisis de muestras de sitios con presencia Inca, donde también se observa la presencia de animales silvestres (vicuña) y domésticos (llama) y alerta sobre las diferencias de manejo y utilización en ambos tipos de animales (Mengoni Goñalons 2007). 
Lo que se puede observar entonces en los puestos de altura de la Puna es que la mayor parte de los conjuntos están representados por animales silvestres, principalmente vicuña, lo cual es razonable ya que es un recurso típico del área, que parece haber tenido alta disponibilidad y buena accesibilidad a lo largo de todo el proceso agropastoril. Esto parece cumplirse más allá de la evolución de las condiciones paleoambientales que durante buena parte del Tardío, especialmente entre ca. 900-1100 años AP, fueron extremadamente áridas (Olivera et al. 2004). El hecho es llamativo ya que coincide, por ejemplo, en Antofagasta de la Sierra con la expansión de la agricultura intensiva y extensiva con tecnología hidráulica en diversos sectores del fondo de cuenca. Por un lado, hemos sugerido que las decisiones humanas toman diferentes direcciones ante situaciones de cambio ambiental, no existiendo una relación directa entre ambos (Olivera y Grant 2009). Por otro lado, la disponibilidad de fuentes de agua permanente aún en épocas de mayor aridez, debidas a un régimen hidrográfico que se alimenta de nieves permanentes y aguas subterráneas, permitió un manejo del ambiente para la práctica agropastoril asociado a la incorporación de la nueva tecnología agrícola (Tchilinguirián y Olivera 2009).

Asimismo, esto funcionó para la disponibilidad de vegas y otros sectores de pastura, lo que permite inferir que la disminución de las poblaciones de vicuña no habría sido tan importante. En la puna norte, de acuerdo a los registros arquefaunísticos (Yacobaccio et al. 1997-1998), la disminución de la fauna silvestre no habría sido tampoco dramática.

En resumen, las relaciones entre la disponibilidad de biomasa y las condiciones de aridez no pueden entenderse sino en un contexto integral de las variables ambientales.

Otro elemento interesante resultan los análisis de isótopos estables sobre individuos de las poblaciones del Tardío que tienen, en ese sentido, la posibilidad de aportar información relevante. Los estudios realizados parecen apuntar, en general, a que las poblaciones puneñas poseían una dieta bastante generalizada donde las proteínas animales y vegetales, sumadas a la ingesta de hidratos de carbono de plantas C3 y C4, aseguraban una nutrición variada y relativamente equilibrada (Olivera y Yacobaccio 2002).

Lo contemplado en párrafos anteriores tiene interesantes implicaciones para la economía y la dieta de los grupos humanos del Tardío, ya que conlleva a la posibilidad de disponer de recursos de carne importantes a partir de tropas de vicuñas silvestres, sin tener que recurrir de manera permanente e inevitable a los animales del rebaño. Estos últimos pudieron haberse reservado para objetivos más especializados (carga y fibra), actuando al mismo tiempo como una suerte de reaseguro para momentos de escasez. Esta estrategia podría ser efectiva para controlar la alta impredictibilidad climática interanual y disminuir el riesgo propio del ambiente.

El registro de los sitios de Real Grande y Alero Tomayoc, indican que los puestos de altura jugaron un rol destacado dentro de la mencionada estrategia de optimización dirigidos, por un lado, a asegurar el aprovechamiento del más amplio espectro posible de recursos, pero también contribuyendo a la dinámica de control y aprovechamiento de la variedad ambiental puneña en aspectos relacionados con la circulación de información, bienes y energía imprescindibles para el desarrollo de una sociedad social y políticamente cada vez más compleja.

\section{Ciudad Autónoma de Buenos Aires, 24 de Junio 2009}

\section{Agradecimientos}

A todos los compañeros del equipo del Proyecto Arqueológico de Antofagasta de la Sierra, por su apoyo permanente. A la Dra. D. Lavallée y su equipo, que nos permitió revisar el material de Alero Tomayoc. Al Dr. Andrés Izeta y el Comité Científico de la revista por permitirnos participar de esta publicación. Este trabajo contó con los aportes financieros de CONICET (PIP 6333), Agencia Nacional de Promoción Científica y Tecnológica (PICT 26023) y Universidad de Buenos Aires (Programa UBACYT F182 y F122). Las opiniones vertidas en el trabajo son de exclusiva responsabilidad de los autores.

\section{Bibliografía}

Belotti López de Medina, C. 2007. Zooarqueología del sitio Soria 2 (Depto. De San José, Pcia. de Catamarca) y estudio comparativo del registro zooarqueológico del sur de los valles calchaquíes, para los periodos Formativo y Desarrollos Regionales (Siglos I A.C. y XV D.C.). Tesis de Licenciatura inédita. Facultad de Filosofía y Letras, UBA.

Castro Lucic, M. 2000. Llameros de Puna Salada en los Andes del Norte de Chile. En: Pastoreo Altoandino. Realidad, sacralidad y posibilidades, editado por J. Flores Ochoa y Y. Kobayashi, pp. 85-109. Plural Editores - Museo Nacional de Etnografía y Folklore (MUSEF), La Paz.

Elkin, D. 1995. Volume Density of South American Camelid Skeletal Parts. International Journal of Osteoarchaeology, 5: 29-37.

Elkin, D. 1996. Arqueozoología de Quebrada Seca 3: Indicadores de Subsistencia Temprana en la Puna Meridional Argentina. Tesis Doctoral inédita. Facultad de Filosofía y Letras, Universidad de Buenos Aires.

Elkin, D., C. M. Madero, G. L. Mengoni Goñalons, D. E. Olivera y H. D. Yacobaccio. 1991. Avances en el estudio arqueológico de los camélidos del Noroeste Argentino. Actas de la VII Convención Internacional de Especialistas en Camélidos Sudamericanos. Jujuy. En prensa

Escola, P. S. 1996. Riesgo e incertidumbre en economías 
agropastoriles: consideraciones teórico-metodológicas. Arqueología 6: 9-24.

Escola, P. S. 1999. Tecnología Lítica y Sociedades Agropastoriles Tempranas. Tesis Doctoral inédita. Facultad de Filosofía y Letras, Universidad de Buenos Aires.

Göebel, B. 1994. El manejo del riesgo en la economía pastoril de Susques. Zooarqueologia de Camélidos 1: 43-56. Buenos Aires, GZC.

Göebel, B 2001. El ciclo anual de la producción pastoril en Huancar (Jujuy, Argentina) En El uso de los camélidos a través del tiempo, editado por G. Mengoni Goñalons, D. Olivera y H. Yacobaccio, pp. 91-115. Del Tridente, Buenos Aires.

Goñi, R. A. y D. Olivera, 1996. La caza como variable independiente: Análisis comparativo de registros arqueológicos de la Puna y Patagonia argentinos. En Proceedings of the XIII Congress International Union of Prehistoric and Protohistoric Sciences, vol. 6, pp. 13691378, A.B.A.C.O. Edizione, Forli.

Grant, J. 2008. El recurso Camelidae en sitios de Antofagasta de la Sierra (Puna Meridional Argentina:) una aproximación osteométrica. Tesis de Licenciatura inédita. Facultad de Filosofía y Letras, UBA.

Grant, J. 2009. Aportes de distintas técnicas osteométricas para la identificación interespecífica de camélidos sudamericanos. I Congreso Nacional de Zooarqueología. Malargüe. Mendoza, Argentina. En Evaluación

Izeta, A. 2004. Zooarqueología del sur de los valles Calchaquíes. Estudio de conjuntos faunísticos del Período Formativo. Tesis Doctoral inédita. Facultad de Ciencias Naturales y Museo, La Plata.

Kent, J. D. 1982. The Domestication and Exploitation of the South American Camelids: Methods of Analysis and Their Application to Circum-Lacustrine Archaeological Sites in Bolivia and Peru. Tesis Doctoral inédita. Washington University-St. Louis. University Microfilms.

Lavallée, D.; M. Julien; C. Karlin; L. García; D. Pozzi-Escot y M. Fontugne .1997. Entre Desierto y Quebrada: Tomayoc, un alero en la Puna. Avances en Arqueología, 3: 9- 39. IIT, F.F. y L., UBA.

Lavallée, D. y L. García. 1992. Excavaciones en el alero de Tomayoc, 1987-1989. Cuadernos, 3: 7-11. Facultad de Humanidades y Ciencias Sociales, Jujuy.

López, G. 2003. Pastoreo y caza de camélidos en el Temprano de la Puna de Salta: Datos osteométricos del sitio Matancillas 2. Intersecciones en Antropología, 4: 17-27.

López Campeny, S. M., D. Olivera, V. Fernandez Varela y
J. Peña 2005. Procesos tafonómicos, subsistencia y uso del espacio: Análisis de la arqueofauna de un sitio agropastoril de la Puna Meridional argentina (Punta de la Peña 9, Antofagasta de la Sierra, Catamarca). Intersecciones en Antropología 6: 11 -28.

Madero C. y H. Yacobaccio. 1994. EL registro faunístico del Pastoreo Actual y sus Implicaciones Arqueológicas. Zooarqueología de Camélidos 1: 73-94. Grupo Zooarqueología de Camélidos, Buenos Aires.

Meadow, R.1987. Techniques for comparing bone measurement data from small simples. Paper presented at the Northeastern Faunal Analysis Conference. Storrs, Connecticut.

Menegaz, A.N., F. Goin, C. Salemme y E. Ortiz Jaureguizar. 1988. Una propuesta de sistematización de los caracteres morfométricos de los metapodios y falanges de Camelidae. En De Procesos, Contextos y otros Huesos, editado por N. Ratto y A. Haber, pp. 53-64. Instituto de Ciencias Antropológicas (FFyL-UBA).

Mengoni Goñalons, G. L. y H. D. Yacobaccio. 2006. The domestication of South American camelids. A view from the South-Central Andes. En Documenting domestication. New genetic and archaeological paradigms, editado por M. Zeder, D. Bradley, E. Emshwiller y B. Smith, pp.228-244. University of California Press.

Mengoni Goñalons, G. L. 2007. Camelid management during Inca times in N. W. Argentina: models and archaeozoological indicators. Anthropozoologica, 42 (2): 129-141:

Merlino R. J. y M. A. Rabey. 1978 El ciclo agrario-ritual en la Puna Argentina. Relaciones, XII (2): 47-70. Sociedad Argentina de Antropología, Buenos Aires.

Miller, G y R. Burger 1995. Our father the cayman, our dinner the llama: animal utilization at Chavín de Huantar, Peru. American Antiquity 60(3): 421-458.

Muscio, H. 1998-1999. Tendencias en la variabilidad ambiental de la Puna Argentina: Implicancias para la Ecología Humana Prehistórica y para los Paisajes Arqueológicos. Cuadernos del Instituto Nacional de Antropología y Pensamiento Latinoamericano 18:271-296.

Nuñez L. y C. S. Santoro. 1988. Cazadores de la puna seca y salada del área centro-sur Andina (Norte de Chile). Estudios Atacameños 9: 11-60.

Olivera, D. 1991. El formativo en Antofagasta de la Sierra (Puna Meridional Argentina): Análisis de sus posibles relaciones con contextos arqueológicos Agro-alfareros Tempranos del Noroeste Argentino y Norte de Chile. Actas del IX Congreso Nacional de Arqueología Chilena, 2: 6178. Chile, Sociedad Chilena de Arqueología. 
Olivera, D. 1997. La importancia del Recurso Camelidae en la Puna de Atacama entre los 10.000 y 500 años A.P. Estudios Atacameños. Tomo Especial dedicado al II Taller Binacional de Interacción entre el NOA y el Norte Chileno, 14: 29-41. San Pedro de Atacama, Chile.

Olivera, D. 2006. Recursos bióticos y subsistencia en Sociedades Agropastoriles de la Puna Meridional Argentina. Comechingonia 9: 19-56.

Olivera, D. y D. Elkin. 1994. De Agricultores y Pastores: El proceso de domesticación en la puna Meridional Argentina. Zooarqueología de Camélidos 1: 95-124. Grupo Zooarqueología de Camélidos, Buenos Aires.

Olivera, D. y L. Grana. 2005. Controles tafonómicos en conjuntos arqueofaunísticos de un sitio de la Puna de Atacama: Las ocupaciones tardías del Alero Tomayoc (Jujuy, Argentina) MS.

Olivera, D. y J. Grant. 2009. Economía y Ambiente durante el holoceno tardío (ca. 4500-400) de Antofagasta de la Sierra (Puna Meridional Argentina). En Temas de Arqueología: Estudios tafonómicos y zooarqueológicos (1), compilado por A. Acosta, D. Loponte y L. Mucciolo, pp. 99-131.

Olivera, D., P. Tchilinguirian y L. Grana. 2004. Paleoambiente y Arqueología en la Puna Meridional Argentina: archivos ambientales, escalas de análisis y registro arqueológico. Relaciones de la Sociedad Argentina de Antropología XXIX: 229-247.

Olivera D y S. Vigliani 2000-2002. Proceso cultural, uso del espacio y producción agrícola en la Puna Meridional Argentina. Cuadernos del Instituto Nacional de Antropología y Pensamiento Latinoamericano 19: 458-481. Buenos Aires.

Olivera, D. y H. Yacobaccio 2002. Estudios de Paleodieta en Poblaciones Humanas de los Andes del Sur a Través de Isótopos Estables. Actas del V Congreso Nacional de Paleopatología, Alcalá la Real, España. (En CD e http:// www.ucm.es/info/aep/boletín/actas/24.pdf).

Pagliaro, M. 1995 Análisis de la economía pastoril en una localidad de la puna jujeña: manejo del espacio y el riesgo productivo. Cuadernos 16: 103-119. Instituto Nacional de Antropología y Pensamiento Latinoamericano, Buenos Aires.

Panebianco, A., J. Grant y D. Olivera. 2005. Análisis de variables cuantitativas y cualitativas en material arqueofaunístico de la Puna Meridional Argentina. Actas del I Congreso Argentino de Arqueometría, editado por A. Pifferetti y R. Bolmaro, pp. 27-28.

Reigadas, M. C. 2008. Explotación de recursos animales y producción textil durante el Holoceno (Antofagasta de la Sierra, Catamarca, Argentina). Estudios Atacameños 35: $35-48$.

Romo Marty, M. 1998 Pastores del Sur Andino. Percepción y representación del ambiente. Estudios Atacameños 16: 209-231.

Santoro, C. y L. Nuñez A. 1987. Hunters of the Dry Puna and the Salt Puna in northern Chile. Andean Past 1:57109.

Tarragó, M. 2000. Chacras y pukara. Desarrollos regionales tardíos. En Nueva Historia Argentina, Los pueblos Originarios y la Conquista, editado por M. Tarragó, pp. 257-299. Sudamericana, Buenos Aires

Tchilinguirian y Olivera 2009. Evolution and Human Land Management during the Holocene in southern altiplan desert, Argentina $\left(26^{\circ} \mathrm{S}\right)$. En Land Degradation and Desertification: assessment, mitigation and remediation, editado por P. Zdruli, M. Pagliai, S. Capur y A. Faz Cano. Springer, Holanda. En prensa.

von Den Driesch, A. 1976. A Guide to the Measurement of Animal Bones from Archaeological Sites. Peabody Museum of Archaeology and Ethnology, Harvard

Wheeler J.C. 1991. Origen, evolución y status actual. En: Fernández-Baca S (ed) Avances y perspectivas del conocimiento de los camélidos sudamericanos: 11-48. Oficina Regional de la FAO para América Latina y el Caribe, Santiago, Chile.

Wing, E. 1972. Utilization of animal resources in the Peruvian Andes. Andes 4: Excavations at Kotosh, Peru 1963 and 1964, editado por I. Seiichi y K. Terada, pp. 327-351. Tokyo University

Winterhalder, B.; F. Lu y B. Tucker. 1999. Risk-Sensitive Adaptive Tactics: Models and Evidence from Subsistence Studies in Biology and Anthropology. Journal of Archaeological Research 7(4): 301-348.

Yacobaccio, H. 1994. Biomasa animal y Consumo en el Pleistoceno-Holoceno Surandino. Arqueología 4: 43-71. Buenos Aires, Inst. Cs. Antropológicas, UBA.

Yacobaccio, H., D. Elkin y D. Olivera. 1994. ¿El fin de las sociedades cazadoras?: El proceso de domesticación animal en los Andes Centro-Sur. Arqueología Contemporánea 5, Edición Especial: "Arqueología de CazadoresRecolectores" (L.Borrero y L. Lanata comp.), pp. 23-32. Buenos Aires.

Yacobaccio, H. D., C. M. Madero, M. P. Malmierca, M. C. Reigadas 1997-1998. Caza, domesticación y pastoreo de camélidos en la Puna Argentina. Relaciones de la Sociedad Argentina de Antropología XXII-XXIII: 389-418. 